\title{
Investigation into the effects of antioxidant-rich extract of Tamarindus indica leaf on antioxidant enzyme activities, oxidative stress and gene expression profiles in HepG2 cells
}

Nurhanani Razali, Azlina Abdul Aziz, Chor Yin Lim, Sarni Mat Junit

The leaf extract of Tamarindus indica L. ( $T$. indica) had been reported to possess high phenolic content and showed high antioxidant activities. In this study, the effects of the antioxidant-rich leaf extract of the $T$. indica on lipid peroxidation, antioxidant enzyme activities, $\mathrm{H}_{2} \mathrm{O}_{2}$-induced ROS production and gene expression patterns were investigated in liver HepG2 cells. Lipid peroxidation and ROS production were inhibited and the activity of antioxidant enzymes superoxide dismutase, catalase and glutathione peroxidase was enhanced when the cells were treated with the antioxidant-rich leaf extract. cDNA microarray analysis revealed that 207 genes were significantly regulated by at least 1.5fold $(p<0.05)$ in cells treated with the antioxidant-rich leaf extract. The expression of KNG1, SERPINC1, SERPIND1, SERPINE1, FGG, FGA, MVK, DHCR24, CYP24A1, ALDH6A1, $E P H X 1$ and $L E A P 2$ were amongst the highly regulated. When the significantly regulated genes were analyzed using Ingenuity Pathway Analysis software, "Lipid Metabolism, Small Molecule Biochemistry, Hematological Disease' was the top biological network affected by the leaf extract, with a score of 36 . The top predicted canonical pathway affected by the leaf extract was the coagulation system $\left(P<2.80 \times 10^{-6}\right)$ followed by the superpathway of cholesterol biosynthesis $\left(P<2.17 \times 10^{-4}\right)$, intrinsic prothrombin pathway $\left(P<2.92 \times 10^{-4}\right)$, immune protection/antimicrobial response $\left(P<2.28 \times 10^{-3}\right)$ and xenobiotic metabolism signaling $\left(P<2.41 \times 10^{-3}\right)$. The antioxidant-rich leaf extract of $T$. indica also altered the expression of proteins that are involved in the Coagulation System and the Intrinsic Prothrombin Activation Pathway (KNG1, SERPINE1, FGG), Superpathway of Cholesterol Biosynthesis (MVK), Immune protection/antimicrobial response (IFNGR1, LEAP2, ANXA3 and MX1) and Xenobiotic Metabolism Signaling (ALDH6A1, ADH6). In conclusion, the antioxidant-rich leaf extract of $T$. indica inhibited lipid peroxidation and ROS production, enhanced antioxidant enzyme activities and significantly regulated the expression of genes and proteins involved with consequential impact on the coagulation system, cholesterol biosynthesis, xenobiotic metabolism signaling and antimicrobial response. 
1 Investigation into the effects of antioxidant-rich extract of Tamarindus indica leaf on antioxidant

2

3

4

5

6

7

8 *Corresponding author:

9 Sarni Mat Junit

10 Department of Molecular Medicine,

11 Faculty of Medicine,

12 University of Malaya, 50603,

13 Kuala Lumpur,

14 Malaysia

15 Tel: +6 0379674718

16 Fax: +6 0379674957

17 E-mail: sarni@um.edu.my

18

19

20
Lumpur, Malaysia. 
Abstract

The leaf extract of Tamarindus indica L. (T. indica) had been reported to possess high phenolic content and showed high antioxidant activities. In this study, the effects of the antioxidant-rich leaf extract of the $T$. indica on lipid peroxidation, antioxidant enzyme activities, $\mathrm{H}_{2} \mathrm{O}_{2}$-induced ROS production and gene expression patterns were investigated in liver HepG2 cells. Lipid peroxidation and ROS production were inhibited and the activity of antioxidant enzymes superoxide dismutase, catalase and glutathione peroxidase was enhanced when the cells were treated with the antioxidant-rich leaf extract. cDNA microarray analysis revealed that 207 genes were significantly regulated by at least 1.5 -fold $(\mathrm{p}<0.05)$ in cells treated with the antioxidant-rich leaf extract. The expression of KNG1, SERPINC1, SERPIND1, SERPINE1, FGG, FGA, MVK, DHCR24, CYP24A1, ALDH6A1, EPHX1 and LEAP2 were amongst the highly regulated. When the significantly regulated genes were analyzed using Ingenuity Pathway Analysis software, 'Lipid Metabolism, Small Molecule Biochemistry, Hematological Disease' was the top biological network affected by the leaf extract, with a score of 36. The top predicted canonical pathway affected by the leaf extract was the coagulation system $\left(P<2.80 \times 10^{-6}\right)$ followed by the superpathway of cholesterol biosynthesis $\left(P<2.17 \times 10^{-4}\right)$, intrinsic prothrombin pathway $(P<$ $\left.2.92 \times 10^{-4}\right)$, immune protection/antimicrobial response $\left(P<2.28 \times 10^{-3}\right)$ and xenobiotic metabolism signaling $\left(P<2.41 \times 10^{-3}\right)$. The antioxidant-rich leaf extract of $T$. indica also altered the expression of proteins that are involved in the Coagulation System and the Intrinsic Prothrombin Activation Pathway (KNG1, SERPINE1 and FGG), Superpathway of Cholesterol Biosynthesis (MVK), Immune protection/antimicrobial response (IFNGR1, LEAP2, ANXA3 and MX1) and Xenobiotic Metabolism Signaling (ALDH6A1 and ADH6). In conclusion, the antioxidant-rich leaf extract of T. indica inhibited lipid peroxidation and ROS production, 
enhanced antioxidant enzyme activities and significantly regulated the expression of genes and proteins involved with consequential impact on the coagulation system, cholesterol biosynthesis, xenobiotic metabolism signaling and antimicrobial response.

Keywords: Tamarindus indica leaf, antioxidant, gene expression, cDNA microarray, Ingenuity Pathway Analysis, qRT-PCR, Enzyme-Linked Immunosorbent Assay (ELISA), Western blotting

\section{Introduction}

Research on the role of nutrients on general well-being and disease prevention has gained momentum in recent years. Amongst the nutrients studied, natural sources from plants have been gaining notable attention. Plants and herbs have been widely consumed in many populations of the world mainly as food and for various medicinal benefits. Amongst the multitude of bioactive compounds found in plants and herbs, phenolic compounds that are secondary metabolites, have been widely reported as potent antioxidants (Covas, Nyyssonen, Poulsen et al. 2006; Thangapazham, Passi and Maheshwari 2007; Singh, Mok, Christensen et al. 2008). Numerous findings support the role of phenolics in the prevention of oxidative damage-related diseases including cancers (Le Marchand 2002), cardiovascular diseases (CVD) (Reaven, Khouw, Beltz et al. 1993), osteoporosis and neurodegenerative diseases (Halliwell 1994).

Tamarindus indica L. (T. indica) of which the fruit pulp is widely used as an acidic flavor in cooking, is one of the plants with reported therapeutic properties. $T$. indica belongs to the family of Leguminosae and grows naturally in many tropical and sub-tropical regions. Our group had recently reported that the methanol seed, leaf, leaf veins, fruit pulp and skin extracts of $T$. indica 
possessed high phenolic content and antioxidant activities (Razali, Mat-Junit, Abdul-Muthalib et al. 2012). Amongst these extracts, the methanol leaf extract showed the highest antioxidant activities. The leaves are traditionally used to treat various ailments including cough, worm infection, rheumatism, jaundice, and ulcer (Sreelekha, Vijayakumar, Ankanthil et al. 1993). The methanol leaf extract of $T$. indica has been shown to have antibacterial (Muthu, Nandakumar and Rao 2005; Melendez and Capriles 2006), antimalarial (Asase et al., 2005), antimicrobial (Escalona-Arranz et al., 2010), antiviral (El-Siddig et al., 1999), anticancer (Saleem et al., 2009), anti-inflammatory (Bhadoriya et al., 2012), hepatoprotective and antioxidant (Sudhahar, Kumar, Varalakshmi et al. 2007) activities as well as inhibitory effects on tyrosine phosphatase 1B (Na et al., 2009; Senthil Kumar et al., 2012). The presence of lupanone and lupeol (Imam, Azhar, Hasan et al. 2007), catechin, epicatechin, quercetin and isorhamnetin (Razali et al., 2012) in the leaf extract could have contributed towards the diverse range of the medicinal activities. A recent study reported that the leaf extract of $T$. indica protected the red blood cells by attenuating $\mathrm{H}_{2} \mathrm{O}_{2}$ induced membrane damage and also inhibiting intracellular ROS production (Escalona-Arranz et al., 2014). Molecular evidence to support the beneficial effects of the leaf extract is however, still lacking.

HepG2 cells have long been used as an in vitro model to study cytoprotective, genotoxic and antigenotoxic effects of compounds since they retain many of the specialized functions of normal human hepatocytes (Knasmuller et al., 2004; Mersch-Sundermann et al., 2004). In addition, HepG2 cells have been shown to have the closest similarity in terms of signaling network patterns with those observed in primary hepatocytes (Saez-Rodriguez et al., 2011). HepG2 cells have also been used in nutrigenomics analyses including germinated brown rice (Imam and 
91 Ismail, 2013), T. indica fruit pulp (Razali et al., 2010) and Anacardium occidentale (Khaleghi et

92 al., 2011). Hence, in this study, the effects of the antioxidant-rich methanol leaf extract of $T$.

93 indica on gene expression profile and protein abundance in HepG2 cells, a widely used in vitro

94 model for human liver hepatocytes, were investigated.

95

96 Materials and methods

97 Chemicals

98 All reagents used in the experiments were of analytical grade and obtained mostly from Fluka 99 and Sigma. Solvents used for extraction of plant samples were purchased from Fisher Scientific.

100 The phenolic standards were obtained from Sigma. Water used was of Millipore quality. The 101 human hepatoma, HepG2 cell lines were purchased from ATCC, USA. The growth medium, 102 serum and antibiotics for the cell culture experiments were purchased from Flowlab, Australia.

Preparation of the methanol leaf extract of $T$. indica

The leaves of $T$. indica were collected from Kedah in the northern region of Malaysia and were processed within a day of harvesting. The plant was deposited in the Rimba Ilmu Herbarium, University of Malaya with a voucher specimen of KLU 45976. The methanol leaf extract of $T$. indica was prepared as previously described (Razali, Mat-Junit, Abdul-Muthalib et al. 2012). Briefly, the dried powdered samples were extracted with methanol at room temperature for $24 \mathrm{~h}$ with a mass to volume ratio of 1:20 $(\mathrm{g} / \mathrm{mL})$. The extracts were evaporated to dryness on the

111 rotary evaporator at $37^{\circ} \mathrm{C}$ and the residues were re-dissolved in $10 \%$ DMSO. Extracts were kept 112 at $-20^{\circ} \mathrm{C}$ until further analyses. 
114 Cell culture

115 The human liver cells line, HepG2 (ATCC, Manassas VA, USA) were grown in Dulbecco's 116 modified Eagle's medium (DMEM) supplemented with 10\% foetal bovine serum (Flowlab, 117 Australia), 1\% penicillin (Flowlab, Australia) and 1\% streptomycin (Flowlab, Australia). Cells 118 were maintained in humidified air with $5 \% \mathrm{CO}_{2}$ at $37^{\circ} \mathrm{C}$.

119

120 Cell viability analysis using the MTT assay

121 Cell viability assay was carried out using 3-(4,5-dimethylthiazol-2-yl)-2,5-diphenyltetrazolium 122 bromide (MTT) as described by Mosmann, 1983, with minor modifications (Denizot and Lang 123 1986; Hansen, Nielsen and Berg 1989). Briefly, HepG2 cells at a density of 5,000 cells per well 124 were seeded in a 96-well ELISA microplate. The cells were incubated at $37^{\circ} \mathrm{C}$ in $5 \% \mathrm{CO}_{2}$ for 24 $125 \mathrm{~h}$. After $24 \mathrm{~h}$, the plant extracts, at various concentrations $(0-600 \mu \mathrm{g} / \mathrm{ml})$ were added into the 126 wells and the cells were further incubated for $48 \mathrm{hr}$. After $48 \mathrm{~h}$, MTT reagent (Merck) was added 127 and the mixture was incubated for $4 \mathrm{~h}$. Then, the mixtures in each well were removed and 128 formazan crystals formed were dissolved in 75\% isopropanol. Spectrophotometry measurement 129 of the mixture was performed using a microplate-reader (Bio-Rad) at wavelengths of 570 and $130620 \mathrm{~nm}$. A log plot of cell viability (\%) against the concentrations of plant extracts was 131 constructed. From the plot, a near non-toxic concentration $\left(\mathrm{IC}_{20}\right)$ of the extracts was calculated 132 and used for the subsequent analyses on antioxidant activities and gene expression patterns in 133 HepG2 cells treated with the leaf extract. The concentration of the leaf extract that reduced cell 134 viability by $50 \%\left(\mathrm{IC}_{50}\right)$ was also calculated from the plot (Razali, Aziz and Junit 2010). 135

136 Evaluation of lipid peroxidation and antioxidant enzyme activities 
137 HepG2 cells were seeded and pre-treated with the $\mathrm{IC}_{20}$ concentration of the plant extracts.

138 Following the pre-treatment with the extracts, HepG2 cells were exposed to oxidative stress

139 condition by induction with $1 \mathrm{mM}$ of $\mathrm{H}_{2} \mathrm{O}_{2}$ for $2 \mathrm{~h}$. After $24 \mathrm{~h}$, the cells were subsequently

140 washed with ice-cold PBS and detached using a scraper. Cells were then collected into a

141 microtube and centrifuged for $10 \mathrm{~min}$ at $8000 \mathrm{x}$ g at $4^{\circ} \mathrm{C}$. The supernatant was discarded and the

142 cell pellets were lyzed in Tris- $\mathrm{HCl}$ buffer $(25 \mathrm{mM}, \mathrm{pH}$ 7.4). The lyzed cells were then sonicated

143 for 5 min at $60 \%$ amplitude. Protein content of each sample was quantified using Bradford

144 assay, employing bovine serum albumin (BSA) as the standard (Ausubel, R., Kingston et al.

145 1999). Hundred $\mu \mathrm{g} / \mathrm{ml}$ of protein was used in the lipid peroxidation and antioxidant enzyme 146 assays.

Inhibition of lipid peroxidation

149 Levels of lipid peroxidation in the treated cells were determined by measuring the production of 150 malondialdehyde (MDA) in the presence of thiobarbituric acid (TBA) (Inal, Kanbak and Sunal 151 2001). The TBA reagent used in this assay consisted of a mixture of TBA, trichloroacetic acid 152 (TCA) and $70 \%$ perchloric acid $\left(\mathrm{HClO}_{4}\right)$ in distilled water. Tetraethoxypropane (TEP) in ethanol was used as the standard. Briefly, $0.5 \mathrm{ml}$ of TBA reagent was added to $0.1 \mathrm{ml}$ sample or standard and boiled for $20 \mathrm{~min}$. The mixture was left to cool and was centrifuged for $10 \mathrm{~min}$ at $960 \mathrm{xg}$ at $25^{\circ} \mathrm{C}$. The supernatant was pipetted into a 96-well plate and absorbance was measured at $532 \mathrm{~nm}$ on a microplate reader. All experiments were done in triplicate. The amounts of MDA in the treated and untreated samples were determined using the equation obtained from the standard curve of TEP. Results were expressed as nmol MDA/mg of protein (Awah and Verla 2010). 
160

161 The abundance of 4-hydroxynonenal (4-HNE) protein adducts in both untreated and leaf-treated

Measurement of HNE-protein adduct cells were measured using ELISA kits purchased from Shanghai Qayee, China. Supernatants were collected from the samples and the abundance of protein was detected against 4-HNE (QY-

E05206) according to the manufacturer's protocols. Briefly, $10 \mu 1$ of samples were pipetted into a pre-coated ELISA microplate. The 4-HNE-protein adducts content was probed with an anti HNE-His antibody and was measured by an HRP-conjugated secondary antibody for detection. The plate was washed to remove unbound substances and the end product was measured at 450 nm. A known HNE-BSA standard curve was constructed to determine the concentration of 4HNE protein adducts present in the samples.

\section{Antioxidant enzyme activities}

Activities of the antioxidant enzymes superoxide dismutase (SOD), catalase (CAT) and glutathione peroxidase (GPx) were measured using Assay Kits purchased from Cayman Chemicals (USA). The SOD assay utilized tetrazolium salt for detection of superoxide radicals generated by xanthine oxidase and hypoxanthine. SOD activities were expressed as Unit/ml where one unit is defined as the amount of enzyme needed to exhibit $50 \%$ dismutation of the superoxide radicals.

CAT assay measures the reaction of the enzyme in the presence of an optimal concentration of $\mathrm{H}_{2} \mathrm{O}_{2}$. The reaction produced formaldehyde, which was measured colorimetrically with 4-amino3-hydrazino-5-mercapto-1,2,4-triazole (Purpald) as the chromogen. Purpald specifically forms a bicyclic heterocycle with aldehydes, which upon oxidation changes from colorless to purple. 
183 Formaldehyde concentration in the cells was measured using equation obtained from the linear

184 regression of the standard curve. CAT activities in the samples were expressed in $\mathrm{nmol}_{2} \mathrm{H}_{2}$ $185 \mathrm{oxidized} / \mathrm{min} / \mathrm{ml}$ of $\mathrm{protein}$.

187 GPx activity was measured through a coupled reaction with glutathione reductase whereby GPx catalyzes the reduction of hydroperoxides, including $\mathrm{H}_{2} \mathrm{O}_{2}$ by reduced glutathione. GPx activities in the cells were initially calculated by determining the changes in absorbance per minute obtained from the standard curve. One unit of activity is defined as the amount of enzyme that caused the oxidation of $1.0 \mathrm{nmol}$ of $\mathrm{NADPH}$ to $\mathrm{NADP}^{+}$per minute.

Assay for reactive oxygen species (ROS)

ROS production was assessed using the method of Wang and Joseph (1999) with minor modifications. HepG2 cells were plated into black 96-well plates, seeded and treated as previously described. At the end of the treatment, the medium was removed and the cells were washed with PBS and then incubated with $100 \mathrm{mM}$ dichlorofluorescein diacetate (DCF-DA) in PBS for $30 \mathrm{~min}$ at $37^{\circ} \mathrm{C}$. The formation of the fluorescent-oxidized derivative of DCF-DA was monitored at emission wavelength of $530 \mathrm{~nm}$ and excitation wavelength of $485 \mathrm{~nm}$ in a fluorescence multi-detection reader (Synergy HTTM Multi-detection microplate reader; BioTek Instruments Inc, VT, USA). ROS production was expressed as unit of fluorescence (UF)

202 produced by DCF-DA/mg of total protein (UF $\times 10^{4} / \mathrm{mg}$ of proteins) (Marabini, Frigerio, 203 Chiesara et al. 2006). 
206 Gene expression analyses in HepG2 cells treated with the methanol leaf extract of $T$. indica

207 HepG2 cells were seeded at a density of $3.0 \times 10^{6}$ in a $25 \mathrm{~cm}^{2}$ flask. The cells were then treated

208 with an $\mathrm{IC}_{20}$ concentration of the methanol leaf extract of $T$. indica for $24 \mathrm{~h}$. Following this, cells

209 were trypsinized and then precipitated by centrifugation at $130 \mathrm{x} \mathrm{g}$ for $5 \mathrm{~min}$. Cells were washed

210 with PBS twice before total cellular RNA (tcRNA) was extracted from the cells. tcRNA from

211 both untreated and $T$. indica leaf-treated HepG2 cells was isolated and then purified using

212 RNAEasy kit (Qiagen) according to the manufacturer's instructions. The quality and the

213 concentration of the extracted RNA was determined using NanoDrop 8000 spectrophotometer

214 (Thermo Scientific, DE, USA). Only samples with a 260/280 ratio of above 1.8 indicative of

215 good quality, were used for further analyses. The integrity of the tcRNA was assessed using

216 RNA 6000 Nano LabChip kit in an Agilent 2100 Bioanalyzer (Agilent Technologies, Santa

217 Clara, CA) as recommended by the manufacturer. Data were archived automatically in the form

218 of electropherogram, gel-like images and tables containing sample concentration and the

$21928 \mathrm{~S} / 18 \mathrm{~S}$ ratio of the ribosomal subunits. Eukaryotic total cellular RNA integrity calculated using

220 RIN software algorithm, follows a scale of 1 to 10 , with 1 being the most degraded profile and

22110 being the most intact (Schroeder, Mueller et al. 2006).

222

223

cDNA microarray analysis

224 Gene expression analysis was performed on the Affymetrix Human Gene 1.0 S.T (sense target) arrays according to the Affymetrix eukaryotic RNA labelling protocol (Affymetrix). Briefly, the tcRNA (100 ng) extracted from the untreated and the T. indica leaf-treated HepG2 cells was first converted to single-stranded sense strand DNA (cDNA) in two cycles using the whole transcript

228 (WT) cDNA synthesis, amplification kit and sample clean-up module. The sense strand DNA 
was then fragmented, biotinylated and hybridized to the Affymetrix Human Gene 1.0 S.T array

230 at $45^{\circ} \mathrm{C}$ for $16 \mathrm{~h}$ in hybridization Oven 640 . After hybridization, the arrays were stained and then

231 washed in the Affymetrix Fluidics Station 450 under standard conditions. The stained arrays

232 were then scanned at $532 \mathrm{~nm}$ using an Affymetrix GeneChip Scanner 3000, and CEL files for

233 each array were generated using the Affymetrix Gene-Chip Operating Software (GCOS).

Microarray data normalization and analyses

Partek Genomic Suite software was used to convert the CEL files into text files, thus listing all the up-regulated and down-regulated genes in response to the treatment. The gene set annotation was verified using Netaffx Analysis Center software. The gene sets were then subjected to a oneway analysis of variance (ANOVA) in the Partek Genomic software to determine significantly expressed sets of genes, which was set according to $\mathrm{P}$ value less than $0.05(\mathrm{P}<0.05)$. Significantly expressed genes were then re-filtered to include only those with fold change difference of equal to or greater than 1.5. Following the filtration of the genes list, those significant genes were subjected to Gene Ontology (GO) Enrichment tool in the Partek Genomic

Suite Software for additional information and further classification on the biological functions of the genes and the genes products. Information on function of genes can be derived from the Gene Ontology database, which provides a structured annotation of genes with respect to molecular

247 function, biological process and cellular component. Further information on GO could be retrieved from http://www.geneontology.org/. All or some selected high significantly expressed genes were then clustered and grouped in hierarchical clustering using Genesis software (Sturn et al., 2002). 
252 Pathway interactions and biological process analyses

253 Functional analyses to predict networks that are affected by the differentially expressed proteins 254 were carried out using Ingenuity Pathways Analysis (IPA) software (Ingenuity® Systems, 255 http://www.ingenuity.com/). Details of the proteins (encoded by the genes of which the 256 expression is significantly altered), their quantitative expression values (fold change difference 257 of at least 1.5$)$ and $\mathrm{p}$ value $(\mathrm{p}<0.05)$ were imported into the IPA software to predict biochemical 258 networks that are affected in HepG2 cells in response to the leaf extract of $T$. indica treatment. Each protein identifier was mapped to its corresponding protein object and was overlaid onto a 260 global molecular network developed from information contained in the Ingenuity Knowledge Base. Network predictions based on the protein input were generated algorithmically by utilizing the information contained in the Ingenuity Knowledge Base. Right-tailed Fischer's exact test was used to calculate a $\mathrm{p}$ value indicating the probability that each biological function assigned to the network is due to chance alone.

Validation of the microarray data using real-time RT-PCR (qRT-PCR)

Reverse transcription of tcRNA (1000 ng) into complementary DNA (cDNA) was performed using a High Capacity RNA-to-cDNA Master Mix (Applied Biosystems) following the manufacturer's instructions. The reaction mixture consisted of $1000 \mathrm{ng}$ tcRNA and $1 \mathrm{X}$ Master Mix which contained magnesium chloride $\left(\mathrm{MgCl}_{2}\right)$, deoxyribonucleotide triphosphate (dNTPs), recombinant RNase inhibitor protein, reverse transcriptase, random primers, oligo(dT) primer and stabilizers, was prepared in a final volume of $20 \mu 1$. The reaction mixture was placed in a thermal cycler with the following parameters: $25^{\circ} \mathrm{C}$ for $5 \mathrm{~min}, 42^{\circ} \mathrm{C}$ for $30 \mathrm{~min}$ and $85^{\circ} \mathrm{C}$ for 5 min. The cDNA was kept at $-80^{\circ} \mathrm{C}$ until further analysis. 
Primer pairs for selected up-regulated and down-regulated genes as well as a housekeeping gene,

GADPH, are listed in Table S1. PCR amplification was performed in $0.2 \mathrm{ml}$ MicroAmp®

278 Optical 8-tube strips in a final volume of $20 \mu \mathrm{l}$, consisted of $10 \mu \mathrm{l}$ of $2 \mathrm{X}$ Fast SYBR ${ }^{\circledR}$ Green

Master Mix (Applied Biosystem) containing a mixture of SYBR ${ }^{\circledR}$ Green I dye, AmpliTaq® Fast

DNA Polymerase, UP (Ultra-Pure), Uracil-DNA Glycosylase (UDG), ROXTM Passive

281

282

283

284

285

286

287

288

289

290

291

292

293

294

295

296

297

Reference dye, dNTPs and optimized buffer components, reverse and forward primers (200 nm)

and cDNA (20 ng). qRT-PCR was performed with a PCR parameters consisted of $20 \mathrm{sec}$ of Taq DNA Polymerase activation at $95^{\circ} \mathrm{C}$, followed by 40 cycles of denaturation at $95^{\circ} \mathrm{C}$ for $3 \mathrm{sec}$, primer annealing at $60^{\circ} \mathrm{C}$ for $30 \mathrm{sec}$. The melting curves of the real-time PCR products were analyzed from $65^{\circ} \mathrm{C}$ to $95^{\circ} \mathrm{C}$. Each measurement was carried out in triplicate. Differences in gene expression, expressed as fold-change, were calculated using the $2^{-\Delta \Delta \mathrm{Ct}}$ method where $G A P D H$ was used as the reference gene.

Detection of altered protein expression in HepG2 cells treated with the methanol leaf extract of T. indica

Ten proteins, IFNGR1, LEAP2, SERPINE1, MX1, KNG1, MVK, FGG ANXA3, ALDH6A1 and ADH6 of which the encoding genes were aberrantly expressed in the $T$. indica leaf-treated cells were selected for ELISA analyses. The HepG2 cells $\left(3 \times 10^{6}\right)$ were seeded and treated with an $\mathrm{IC}_{20}$ concentration of the methanol leaf extract of $T$. indica for $24 \mathrm{~h}$. After $24 \mathrm{~h}$, cell lysates were scraped off from the flasks and re-suspended in ice-cold PBS ( $\mathrm{pH} \mathrm{7.4)} \mathrm{and} \mathrm{then} \mathrm{stored}$ overnight at $-20^{\circ} \mathrm{C}$. Cells were subjected to 2 freeze-thaw cycles and the cell lysates were then centrifuged at $5000 \times \mathrm{g}$ for 5 minutes at $4^{\circ} \mathrm{C}$. Supernatants were collected and the presence of 
proteins were detected against MX1 (SEL763Hu), PAI1 (SEA532Hu), KNG1 (SEB267Hu),

ANXA3 (SEE786Hu), FGG (SEC477Hu), MVK (SEH603Hu), ALDH6A1 (SEE836Hu) and

ADH6 (SEE865Hu) from Cloud-clone, Texas, USA, while IFNGR1 (CSB-EL011051Hu) and

LEAP2 (CSB-EL012853Hu) from Cusabio Biotech, Wuhan, China. Standard curves were constructed to determine the concentration of proteins present in the samples. All analyses were done in triplicate.

304

Verification of the ELISA data

To verify the ELISA results, the presence of two proteins, IFNGR1 and SERPINE1, was further assessed using Western blotting. HepG2 cells were seeded and treated as earlier described for ELISA analysis. Proteins were then extracted from cells in modified radio immunoprecipitation assay (RIPA) buffer. Briefly, the cells were washed with ice-cold PBS, trypsinized and lyzed with sufficient amount of ice-cold RIPA buffer (150 mM sodium chloride, $1 \%$ Triton X-100, $0.5 \%$ sodium deoxycholate, $0.1 \%$ sodium dodecylsulphate and $50 \mathrm{mM}$ Tris- $\mathrm{HCl}$ at $\mathrm{pH} 8.0$ ) containing $1 \%$ protease and phosphatase inhibitors.

313

314 Total cell lysate proteins were quantified using bicinchoninic acid (BCA) protein assay kit

315 (Thermo Scientific, IL, USA). Forty $\mu \mathrm{g}$ of the extracted proteins were separated on a $12 \%$ 316 sodium dodecyl sulfate (SDS) polyacrylamide gel and transferred onto polyvinylidene difluoride 317 (PVDF) membranes with $0.45 \mu \mathrm{m}$ pore size (Bio-Rad, CA, USA) at a constant voltage of $100 \mathrm{~V}$, $318350 \mathrm{~mA}$ for $1 \mathrm{~h}$ at $4^{\circ} \mathrm{C}$ in a mini electrophoretic blotting system (C.B.S. Scientific, USA). The 319 blot was then blocked overnight and developed against anti-interferon gamma receptor 1, 320 IFNGR1 (ab61179, Abcam, UK), anti-serpin peptidase inhibitor, clade E, member 1, SERPINE1 
321 (ab66705, Abcam, UK) using the WesternDot 625 Goat Anti-Rabbit Western Blot kit

322 (Invitrogen, Oregon, USA). Anti- $\beta$-actin and Biotin-XX-Goat were used as the reference and

323 secondary antibody, respectively. The membranes were first incubated with biotin-XX-Goat anti-

324 rabbit for $1 \mathrm{~h}$ and then washed thrice with $1 \mathrm{X}$ washing buffer. Following this, the membranes

325 were incubated with Qdot 625 streptavidin nanocrystal for $1 \mathrm{hr}$ and after the final washing step

326 with deionized water, the fluorescence signal was visualized at $300 \mathrm{~nm}$ using a gel doc system

327 (Gel-doc 1000/2000 system, Bio-Rad, USA). The image was digitally captured,

328 densitometrically scanned, quantified and analyzed using ImageJ Software (National Institutes of

329 Health, USA). At least three independent Western blots were quantified for each experiment.

330

331 Statistical analyses

332 All analyses were done in triplicate. Results were expressed as means \pm standard deviation. The 333 data were statistically analyzed using the SPSS statistical software for Windows, Version 21.0.

334 (Armonk, NY: IBM Corp.) An independent t-test was used for comparisons of means between 335 groups. One-way analysis of variance (ANOVA) and Tukey's Honestly Significant Difference 336 test were used to compare means among groups. The level of significance was set at $\mathrm{p}<0.05$. 
Results

340 Cell viability assay

341 The viability of HepG2 cells in response to treatment with different concentrations of the

342 methanol leaf extract of $T$. indica was determined from the log plot of cell viability assay (Figure

343 S1). From the log plot, the concentration of the methanol leaf extract that reduced cell viability

344 by $50 \%\left(\mathrm{IC}_{50}\right)$ was found to be $93.33 \mu \mathrm{g} / \mathrm{ml}$. The highest concentration tested, $600.00 \mu \mathrm{g} / \mathrm{ml}$, 345 reduced cell viability to $2.3 \%$. The $\mathrm{HepG} 2$ cells showed more than $80 \%$ viability $\left(\mathrm{IC}_{20}\right)$ in 346 response to $24.55 \mu \mathrm{g} / \mathrm{ml}$ of the extract. $\mathrm{The}^{\mathrm{IC}_{20}}$ concentration was subsequently used to treat the 347 cells for the antioxidant and microarray gene expression analyses.

349 Evaluation of lipid peroxidation, antioxidant enzyme activities and ROS production in HepG2 350 cells treated with the methanol leaf extract of $T$. indica

Lipid peroxidation

The effects of the methanol leaf extract of $T$. indica in preventing lipid peroxidation in HepG2 cells were investigated. As shown in Figure 1A, induction of oxidative stress by $\mathrm{H}_{2} \mathrm{O}_{2}$ in the untreated HepG2 cells caused the MDA levels to increase up to 3-fold higher than the untreated control cells. A significant reduction in MDA levels was observed in pre-treated cells subjected to induction of oxidative stress. ELISA analysis showed that $\mathrm{H}_{2} \mathrm{O}_{2}$-induced $\mathrm{HepG} 2$ cells displayed approximately 2-fold increase in levels of 4-HNE compared to untreated and uninduced cells (Figure 1B). Pre-treatment of the cells with the leaf extract led to reduction of 4$\mathrm{HNE}$ levels lower than the untreated, $\mathrm{H}_{2} \mathrm{O}_{2}$-induced cells, and even lower than the untreated, uninduced cells. 
362

363

364

365

366

367

368

369

370

371

372

373

374

375

376

377

378

379

380

381

382

383

384

Antioxidant enzyme activities

The ability of the methanol leaf extract of T. indica to influence antioxidant enzyme activities were investigated by treating $\mathrm{HepG} 2$ cells with the $\mathrm{IC}_{20}$ concentration of the plant extract. As shown in Figure 1(C-E), the induction of HepG2 cells with $\mathrm{H}_{2} \mathrm{O}_{2}$ decreased the activities of SOD, CAT and GPx. However, all the antioxidant enzyme activities were significantly enhanced in the cells following pre-treatment with the leaf extract as compared to the untreated and untreated, $\mathrm{H}_{2} \mathrm{O}_{2}$-induced cells.

Assessment of ROS production in HepG2 cells

The effect of the methanol leaf extract of $T$. indica on ROS production was evaluated in HepG2 cells using a cell permeable probe, DCF-DA. The fluorescent intensity is proportional to the amount of peroxides, which are produced by the cells. The higher the ROS amount, the higher the fluorescent intensity. In the present study, DCF-DA staining was applied to examine whether the leaf extract was able to inhibit ROS production in $\mathrm{H}_{2} \mathrm{O}_{2}$-induced HepG2 cells. The ROS activity was expressed as Relative Fluorescence Unit (RFU) (Figure 1F).

Image-based ROS measurement captured by fluorescence microscopy

ROS production increased significantly after HepG2 cells were challenged with $1 \mathrm{mM} \mathrm{H}_{2} \mathrm{O}_{2}$ as compared with the untreated and unchallenged cells (Figure 1F). However, pre-treatment of the cells with $\mathrm{IC}_{20}$ concentration of the leaf extract significantly decreased $\mathrm{H}_{2} \mathrm{O}_{2}$-mediated ROS formation, whereby intensity of the fluorescence was reduced to a level similar to that of the unchallenged cells. This can also be observed when ROS production was captured by fluorescence microscopy (Figure 2A-C). 
385 Gene expression analyses in HepG2 cells treated with the methanol leaf extract of T. indica 386

cDNA microarray data analyses

388 Microarray data were filtered using Partek Genomics Suite software according to P value less than 0.05 and with fold change difference of equal to or greater than 1.5. Principle Component Analysis (PCA) plot was then generated using the same software to indicate the reproducibility of the microarray data (Figure 3A). Biological replicates of control $(n=3)$ and leaf-treated HepG2 cells $(n=3)$ are shown in blue and green respectively. From the plot, it is clear that the control samples were grouped separately from the treated samples. Hierarchical clustering in Figure 3B shows the expression pattern of selected significantly regulated genes in each replicate of the untreated and T. indica leaf-treated cells. Green and red boxes indicate down- and up-regulated 396 genes, respectively. A total of 207 genes were significantly regulated in leaf-treated HepG2 cells.

The complete list of significantly regulated genes is attached in Table S2. Based on GO analyses, 398 the list of highly significant genes categorized under their biological functions with details of the GenBank accession number, name of the gene and its respective protein, and fold change difference between treated and untreated cells are presented in Table 1. Amongst the significant regulated genes, the expression of $C Y P 24 A 1$ and $S H B G$ showed the highest fold change difference of -4.19 and 4.11, respectively. Other significantly regulated genes include $K N G 1$, SERPINC1, SERPIND1, SERPINE1, FGG, FGA, DHCR24, LEAP2, IFNGR1, ANXA3, MX1, ADH6 and ALDH6A1 (Table 1). Similar pattern of expression was generated when selected 405 genes namely AREG, CYP24A1, ANXA3, FGG, FGA, LEAP2, SERPINE1, MVK, DHCR24, IFNGR1, ADH6 and ALDH6A1 were quantitated relative to that of GADPH, using qRT-PCR 407 (Figure 4). 
408 Pathway interactions and biological process analyses of the significantly expressed genes

409 IPA analyses identified "Lipid Metabolism, Small Molecule Biochemistry and Hematological

410 Disease" as the top putative network linking 21 of the significantly regulated genes with other

411 interactomes, with a score of 36 (Table 2). A score of 2 or higher indicates confidence of at least

$41299 \%$ of not being generated by random chance and higher scores indicate greater confidence.

413 "Ophthalmic Disease, Connective Tissue Disorders, Inflammatory Disease" was ranked second 414 with a score of 35 while "Digestive System Development and Function, Organ Morphology, 415 Developmental Disorder" was placed third with a score of 32. Two other networks; 416 "Carbohydrate Metabolism, Small Molecule Biochemistry, Free Radical Scavenging" and 417 "Hereditary Disorder, Neurological Disease, Organismal Injury and Abnormalities" shared a 418 similar score of 24. Figure 5A shows a graphical representation of the predicted molecular 419 relationships between the genes listed under the top networks, which linked them to the top five 420 predicted canonical pathways that are listed in Table 2. IPA identified "Lipid Metabolism, Small 421 Molecule Biochemistry and Hematological Disease" as the top network that linked the genes of 422 altered expression namely KNG1, SERPINC1, SERPIND1, SERPINE1, FGG and FGA, to the 423 two top canonical pathways, "Coagulation System" $\left(P<2.80 \times 10^{-6}\right)$ and "Intrinsic Prothrombin 424 Activation Pathway" $\left(P<2.92 \times 10^{-4}\right)$. This network also linked MVK, DHCR24, LSS and $T M 7 S F 2$ to the second top canonical pathway, "Superpathway of Cholesterol Biosynthesis" $(P<$ 426 $2.17 \times 10^{-4}$ ). On the other hand, both top networks, "Ophthalmic Disease, Connective Tissue 427 Disorders, Inflammatory Disease" and "Digestive System Development and Function, Organ 428 Morphology, Developmental Disorder" linked LEAP2, IFNGR1, ANXA3 and MX1 to the fourth top canonical pathway "Immune Protection/Antimicrobial Response" $\left(P<2.28 \times 10^{-3}\right)$. The next 430 top network, "Carbohydrate Metabolism, Small Molecule Biochemistry, Free Radical 
431 Scavenging" connected ALDH6A1, ALDH9A1, EPHX1, CYP24A1, ADH6 and GSTM4 to the

432 fifth top canonical pathway, "Xenobiotic Metabolism Signaling" $\left(P<2.41 \times 10^{-3}\right)$.

433 Figure 5B shows the IPA graphical representation of ALDH6A1, ADH6 and GSTM4 in the 434 xenobiotic metabolism signaling particularly in the major detoxification process of 4-HNE and 435 MDA, the toxic byproducts from oxidative stress-induced lipid peroxidation. On the other hand, 436 Figure 5C shows the IPA graphical representation of the interaction between SERPINC1, 437 SERPIND1, SERPINE1, KNG1, FGG and FGA with other interactomes in the "Coagulation 438 System", the top predicted canonical pathway that were affected by methanol leaf extract of $T$. 439 indica. Four of the genes, $K N G 1, S E R P I N C 1, F G G$ and $F G A$, were also linked to the third top 440 canonical pathway, "Intrinsic Prothrombin Activation Pathway".

441

442 443 T. indica using ELISA and Western blotting

444

445 446

Figure 6A shows significantly higher levels of ALDH6A1, ADH6, IFNGR1, LEAP2, SERPINE1, MX1, KNG1, MVK and FGG in the cells treated with the antioxidant-rich methanol 447 leaf extract of T. indica compared to the untreated cells. On the other hand, ANXA3 level was 448 significantly lower in the treated cells compared to those untreated. Western blot analysis 449 showed that after normalization with $\beta$-actin, SERPINE1 and IFNGR expression were increased 450 by 2.02 and 2.47 -fold respectively, in the treated cells (Figure 6B).

451 
Discussion

454

455

456

Different parts of $T$. indica are recognized for their various medicinal properties. We have reported earlier that the antioxidant-rich $T$. indica fruit pulp extract was able to significantly regulate the expression of a sizable number of genes (Razali et al., 2010, Lim et al., 2013) and significantly alter protein abundance (Chong et al., 2012; Chong et al., 2013) that are associated with antioxidant activities and lipid metabolisms in HepG2 cells. In addition, our group has recently reported that the leaves of $T$. indica possessed high phenolic contents and had potent antioxidant activities in scavenging free radicals in non-cellular based assays (Razali, Mat-Junit et al. 2012). Catechin, epicatechin and quercetin were detected in the antioxidant-rich leaf extract of T. indica (Razali et al., 2012). Catechin and epicatechin isolated from cocoa showed potent 464 antioxidant activities ( $\mathrm{Gu}$, House, $\mathrm{Wu}$ et al. 2006). Catechin and epicatechin detected in tea prevented oxidative stress in rats' liver by directly altering the subcellular ROS production, 466 glutathione metabolism and cytochrome P450 2E1 activity (Higdon and Frei 2003; Sang, Tian, Wang et al. 2003; Singh, Shankar and Srivastava 2011). However, nutrigenomic analyses to further evaluate the molecular mechanism associated with the medicinal and health benefits of the leaves of T. indica in HepG2 cells have not been widely conducted and reported.

HepG2 cells were pre-treated with the antioxidant-rich methanol leaf extract of $T$. indica, 472 followed by the induction of oxidative damage with $\mathrm{H}_{2} \mathrm{O}_{2}$. This was done to investigate the 473 ability of the antioxidant-rich leaf extract of $T$. indica to enhance antioxidant protection in the 474 cells, hence preventing them from oxidative damage. The cells were not exposed to $\mathrm{H}_{2} \mathrm{O}_{2}$ prior to 
475

476

477

478

treatment with the plant extracts as our aim was to measure the ability of $T$. indica to prevent oxidative damage in the cells, rather than repairing damage after it has occurred.

In this study, the antioxidant-rich methanol leaf extract of $T$. indica was shown to be able to reduce the production of ROS and reduce the levels of malondialdehyde (MDA) levels and 4HNE-protein adducts in HepG2 cells.

Lipid peroxidation is known to be an important factor in the pathology of many diseases associated with oxidative stress. Interaction between ROS and unsaturated lipids especially polyunsaturated fatty acids (PUFAs) forms hydroperoxides which can then be further metabolized to produce a variety of aldehydes, including MDA (Brattin, Glende and Recknagel 1985) and 4-HNE (Esterbauer and Cheeseman, 1990; Spickett, 2013). MDA and 4-HNE were found to be elevated in various diseases (Negre-Salvayre et al., 2008; Reed, 2011) and are widely used as biomarkers for lipid peroxidation (Zhang, Wu et al. 2008). DCF-DA is a fluorogenic dye that measures hydroxyl, peroxyl and other ROS activity within the cell. After diffusion into the cell, DCF-DA is deacetylated by cellular esterases to a non-fluorescent compound, dichlorodihydro fluorescein (DCFH). In the presence of peroxidase, intracellular $\mathrm{H}_{2} \mathrm{O}_{2}$ or $\mathrm{OH} \bullet$ changes DCFH to the highly fluorescent compound DCF (Oh and $\mathrm{Lim}$ 2006). $\mathrm{H}_{2} \mathrm{O}_{2}$ is produced from microsomes and peroxisomes and also by several physiological processes such as inflammatory respiratory burst and oxidative phosphorylation (Valko, Rhodes, Moncol et al. 2006; Chen, Zhong, $\mathrm{Xu}$ et al. 2011). $\mathrm{H}_{2} \mathrm{O}_{2}$ has often been used as a model to investigate the mechanism of cell injury by oxidative stress (Rigoulet, Yoboue and Devin 2011). From this study, it can be speculated that the antioxidant-rich leaf extract might also mediate protection of HepG2 cells against toxicity towards $\mathrm{H}_{2} \mathrm{O}_{2}$ by the inhibition of hepatic lipid peroxidation, supporting previous 
498

499

500

501

502

503

504

505

506

507

508

509

510

511

512

513

514

515

516

517

518

519

520

report by (Ghoneim and Eldahshan 2012). MDA (and HNE) is/are enzymatically catabolized to $\mathrm{CO}_{2}$ and $\mathrm{H}_{2} \mathrm{O}$ by mitochondrial aldehyde dehydrogenase (ALDH), decarboxylase and acetyl CoA synthase or by cytoplasmic phosphoglucose isomerase to methyoglyoxal (MG) and subsequently to D-lactate. HNE can form protein or DNA adducts resulting in further biomolecule damages. Based on the microarray analyses, genes encoding glutathione transferase (GST), ALDH and alcohol dehydrogenase (ADH) were significantly up-regulated. All these proteins were involved in the major detoxification pathways to convert 4-HNE and MDA to less reactive chemical species and control their steady-state intracellular concentrations (Spickett, 2013). 4-HNE metabolism may lead to the formation of corresponding alcohol 1,4-dihydroxy-2nonene (DHN), acid 4-hydroxy-2-nonenoic acid (HNA), and HNE-glutathione conjugate products (Dalleau et al., 2013). The main catabolic reactions of 4-HNE are the formation of 4HNE adducts with glutathione (GSH), which occurs spontaneously or can be catalyzed by GSTs. 4-HNE conjugation with GSH produces glutathionyl-HNE (GS-HNE) followed by NADHdependent ADH catalyzed its reduction to glutathionyl-DHN (GS-DHN) and/or ALDH catalyzed oxidation to glutathionyl-HNA (GS-HNA). Secondly, 4-HNE can be reduced to DHN by aldoketo reductases (AKRs) or ADH. Thirdly, 4-HNE can be oxidized to HNA by ALDH (Zhong and Yin, 2015. On the other hand, MDA metabolism involves its oxidation by mitochondrial ALDH followed by decarboxylation to produce acetaldehyde, which is then oxidized by ALDH to acetate and further to $\mathrm{CO}_{2}$ and $\mathrm{H}_{2} \mathrm{O}$ (Esterbauer et al., 1991). As shown in Figure 5b, the upregulation of $A L D H 6 A 1, A D H 6$ and GSTM4 in the leaf-treated HepG2 cells affected the major detoxification process of 4-HNE and MDA. When analyzed using IPA, all these genes were associated with the top canonical pathway, "Xenobiotic Metabolism Signaling". The findings could explain the potent antioxidant activities of the leaf extract in the previous assays mainly in 
521 inhibiting lipid peroxidation. From the ELISA results, the level of 4-HNE adducts were found to

522 be reduced after the leaf treatment as compared to the untreated HepG2 cells. This was in

523 agreement with the previous analyses which demonstrated the reduced level of MDA in the

524 treated HepG2 cells. In addition, the encoded proteins levels, ALDH6A1 and ADH6, were also

525 increased in response to the leaf extract treatment suggesting that protection against lipid

526 peroxidation in the liver was through an increased degradation of MDA and HNE.

527

528 SOD, GPx and CAT are three of the primary antioxidant enzymes in mammalian cells that are

529 important in oxygen metabolizing cells. These antioxidant enzymes are regarded as the first line

530 of defense against ROS. SODs catalyze the dismutation of superoxide anion radicals into $\mathrm{H}_{2} \mathrm{O}_{2}$

531 and water, while CAT and GPx convert $\mathrm{H}_{2} \mathrm{O}_{2}$ into water, reducing the amounts of $\mathrm{H}_{2} \mathrm{O}_{2}$, hence

532 protecting the cells against oxidative damage (McCord, Keele et al. 1971). The plant extract was

533 shown to increase the activities of SOD, CAT and GPx, further reducing levels of the radicals,

534 superoxide anion and $\mathrm{H}_{2} \mathrm{O}_{2}$, hence lowering peroxidative damage to lipids. However, the

535 increase in enzyme activities was not corroborated with an increase in expression of the encoding

536 genes suggesting that the leaf extract did not directly influence gene transcription but rather, by

537 increasing the activity of the enzymes.

538

539 Results in this study imply that the leaf extract which is rich in phenolics including catechin and

540 epicatechin (Razali, Mat-Junit et al. 2012) may have the ability to directly scavenge ROS and/or

541 free radicals that are produced endogenously in the HepG2 cells. This observation may also

542 explain the potent activity of the leaf extract in inhibiting lipid peroxidation and increasing the

543 antioxidant enzyme activities in the previous results. In the event when MDA and HNE 
544 accumulate in cells, the leaf extract was capable to regulate the expression of the genes and 545 consequently the proteins that are involved in the degradation of the two lipid peroxidation 546 products, MDA and $\mathrm{HNE}$, to ultimately produce $\mathrm{CO}_{2}$ and $\mathrm{H}_{2} \mathrm{O}$.

In addition to the genes encoding GST, ALDH and ADH, a total of 207 genes were significantly regulated when HepG2 cells were exposed to an $\mathrm{IC}_{20}$ concentration of the antioxidant-rich leaf extract of $T$. indica. Comparable pattern was observed when the expression of selected genes including AREG, CYP24A1, ANXA3, FGA, FGG, SEPRINE1, MVK, DHCR24, IFNGR1 LEAP2, ALDH6A1 and $A D H 6$ were quantitated using qRT-PCR, validating the results obtained from the microarray analyses (Gadgil et al., 2005; Morey et al., 2006). When the significantly regulated genes were subjected to IPA analyses, "Lipid Metabolism, Small Molecule Biochemistry, Hematological Disease" was identified as the top biological network associated with the significantly regulated genes with a score of 36 . In addition, the "Coagulation System" was identified as the top canonical pathway linking 6 genes namely SERPINC1, SERPIND1, SERPINE1, KNG1, FGA and FGG that were mainly associated with anticoagulation and coagulation cascades in the coagulation system (Figure 5c). SERPINC1, SERPIND1, SERPINE1 and KNG1 encode anti-thrombin III (ATIII), heparin cofactor II (HCII), plasminogen activator inhibitor-1 (PAI-1) and high molecular weight kininogen (HMWK) protein, respectively, while extract of $T$. indica affect the top canonical pathways by altering the expression of those genes, antimicrobial response. 
567 ATIII belongs to the serpin peptidase inhibitor (SERPIN) family, the largest and most diverse

568 family of protease inhibitors (Rawlings, Tolle et al. 2004). ATIII cooperates with its co-factor,

569 heparin, to effectively regulate coagulation proteases, such as thrombin and coagulation factors,

570 Xa, IXa, XIa, and XIIa, (Siddiqi, Tepler and Fantini 1997) thus, prevents the activation of

571 clotting proteinases in blood except at the site of a vascular injury (Olson, Richard et al. 2010).

572 Deficiencies in ATIII correlated with an increased risk of thrombosis (Siddiqi, Tepler et al. 1997)

573 and CVD (Brouwer, Lijfering et al. 2009). Certain polyphenolic antioxidants namely quercetin

574 (standard quercetin or extracted from plants) showed anticoagulant activities by enhancing ATIII

575 levels (Mozzicafreddo, Cuccioloni et al. 2006; Hsieh, Lin et al. 2007). The leaf extract of $T$.

576 indica have been reported to contain quercetin (Razali, Mat-Junit et al. 2012), suggesting its role

577 in enhancing the expression of the SERPINCI gene, which may subsequently affect the ATIII 578 synthesis and secretion.

ROS on the other hand can mediate intravascular thrombus formation by interfering with mechanisms that normally inhibit activation of the coagulation pathway, thus promoting the pro-

582 thrombic cascade (Gorog and Kovacs 1995). Lipid peroxides for instance, can increase the 583 amount of thrombin produced and can slow down the rate of thrombin decay (Salvemini and Cuzzocrea, 2002). Hence, the ability of the leaf extract of $T$. indica to inhibit lipid peroxidation and prevent ROS generation, together with its high antioxidant activities may be beneficial in providing protection against the development of thrombus.

SERPIND1 encodes for another anticoagulant, heparin cofactor II (HCII). HCII potently inhibits

589 thrombin action by forming a bimolecular complex with dermatan sulfate or heparin 
590 proteoglycans under the endothelial layer in mammalians (Tollefsen, Pestka and Monafo 1983).

591 HCII shares a 30\% amino acid sequence homology to that of ATIII (Baglin, Carrell, Church et 592 al. 2002). Unlike ATIII, HCII exclusively inhibits thrombin and does not inhibit other proteases 593 that are involved in coagulation or fibrinolysis (He, Vicente, Westrick et al. 2002). HCII interacts 594 with dermatan sulfate in the vessel wall after disruption of the endothelium and this interaction 595 regulates thrombus formation thus maintaining blood flow after injury to the arterial endothelium 596 (He, Vicente, Westrick et al. 2002). Defects in SERPIND1, leading to HCII deficiency are the 597 cause of thrombophilia, a haemostatic disorder characterized by a tendency to recurrent 598 thrombosis, causing a hypercoagulation state (Tollefsen, Pestka and Monafo 1983). Quercetin, 599 isolated from Flaveria bidentis, was reported to enhance HCII levels (Guglielmone, Agnese, 600 Nunez Montoya et al. 2002). Quercetin, which was also found in high amount in the leaf extract 601 of $T$. indica (Razali et al, 2012), may be responsible for the reported anticoagulation property of 602 the extract (Mozzicafreddo, Cuccioloni et al. 2006; (Guglielmone, Agnese et al. 2002) by 603 regulating the expression of both SERPINCI and SERPIND1.

In addition to SERPINCI and SERPIND1, the expression of SERPINE1, KNG1, FGA and FGG 606 genes of which the encoded proteins are involved in coagulation cascade, were also significantly up-regulated in HepG2 cells in response to the methanol leaf extract of T. indica. PAI-1 also 608 shares a $30 \%$ amino acid sequence homology to that of ATIII. HMWK, upon binding with prekallikrein, initiates the intrinsic pathway of the coagulation cascade and through a series of 610 events, modulates fibrin clot structure.

612 Fibrinogen plays several key roles in the maintenance of hemostasis (Lang, Johanning, Metzler 
613 et al. 2009) and clot formation (He, Blomback, Jacobsson Ekman et al. 2003; Bolliger, Gorlinger

614 and Tanaka 2010). Fibrinogen molecules act during both cellular and fluid phases of coagulation.

615 In the cellular phase, it facilitates the aggregation of platelets via binding of glycoprotein IIb/IIIa

616 receptors on platelet surfaces (Mosesson 2005). In the fluid phase, it is cleaved by thrombin to

617 produce fibrin monomers, which polymerize to form the basis of the clot thus, provide the

618 structural network required for effective clot formation (Tanaka, Key and Levy 2009).

619 Fibrinogen also functioned as an acute phase reactant, in vivo to help modulate the inflammatory 620 cellular reactions (Levy, Szlam, Tanaka et al. 2012).

621

622 The fibrin clot formation from fibrinogen is dissolved by plasmin. Plasmin is proteolytically 623 released from plasminogen by tissue plasminogen activator (tPA) (Kjalke, Ezban et al. 2001).

624 The activity of tPA is selectively inhibited by PAI-1 (Stringer, van Swieten et al. 1994). PAI-1

625 binds to polymerized fibrin within the thrombus, followed by inhibition of tPA-mediated 626 fibrinolysis (Loskutoff and Samad 1998). The absence of PAI-1 in humans leads to life-long 627 bleeding problems presumably resulting from the development of hyper fibrinolysis (Loskutoff 628 and Quigley 2000). Therefore, PAI-1 is the primary physiological inhibitor of plasminogen 629 activation in vivo, and elevations in plasma PAI-1 appear to promote normal fibrin clearance 630 mechanisms and promote thrombosis (Loskutoff and Samad 1998). PAI-1 is encoded by 631 SERPINE1 which expression was up-regulated in response to the methanol leaf extract of $T$. 632 indica treatment in this study. Previous studies reported that a green tea polyphenol, 633 epigallocatechin-3-gallate, suppressed the expression of tPA, of which, was selectively inhibited 634 by PAI-1 (Maeda-Yamamoto et al., 2003; Ramos, 2008). It is speculated that epicatechin 635 detected in the leaf extract might be involved in regulating the SERPINE1 expression, thus may 
636 possibly inhibit tPA expression. Hence, the presence of both epicatechin and quercetin might

637 possibly contribute towards the anticoagulant properties of the methanol leaf extract of $T$. indica.

638 Four genes, KNG1, SERPINC1, FGG and FGA, were also associated to the "Intrinsic

639 Prothrombin Activation Pathway" further suggesting that the leaf extract was capable in

640 regulating the coagulation cascade probably involving the intrinsic prothrombin activation 641 pathway.

642

643 Excessive formation of blood clots may cause acute thrombus formation and obstruction, thus

644 lead to a series of cardiovascular disease (CVD) complications such as stroke. On the other hand,

645 deficiency in blood clotting might cause prolonged bleeding and led to the development of

646 hypovolemic shock, impaired consciousness, acute renal failure, hypoxia, and progressive

647 respiratory failure. This shows the importance of hemostasis in the coagulation cascade in order

648 to achieve a desired balanced in clot production. Patients with CVD are often given

649 anticoagulants as one of the medications, to prevent or delay blood coagulation and the

650 formation of blood clots. However, many of these drugs, namely heparin, dermatan sulphate and

651 warfarin, carry the risk of prolonged bleeding. Antithrombin inhibits factor $\mathrm{Xa}$, thrombin and

652 other serine proteases. These reactions are relatively slow but are markedly accelerated by 653 anticoagulant drugs binding to antithrombin through a high-affinity pentasaccharide sequence,

654 which produces a conformational change in antithrombin that increases antifactor Xa and 655 antithrombin activity (Gresele Agnelli, 2002). This results in a hypocoagulable state in patients 656 under these anticoagulant drug treatments, which is associated with approximately $20-30 \%$ of 657 patients' mortality (Franchini, 2005). Therefore, the ideal clinical anticoagulant would reliably 658 and predictably inhibit thrombin without substantially increasing the risk of bleeding. A recent 
659

660

661

662

663

664

665

666

667

668

669

670

671

672

673

674

675

676

677

678

679

680

681

study revealed that tamarind leaves did not cause significant haemolysis in human red blood cells (Escalona-Arranz et al., 2014). In the present study, the antioxidant-rich leaf extract of T. indica appeared to target various genes including those in intrinsic prothrombin activation pathway that could contribute towards the regulation of the coagulation cascade and thus provides an alternative approach to the classical anticoagulants. However, further in-depth in vitro and in vivo analyses are required to verify the findings as well as to ensure its safety and efficacy.

The methanol leaf extract of $T$. indica also appeared to affect the "Superpathway of Cholesterol Biosynthesis" by regulating the expression of DHCR24, LSS, MVK and TM7SF2 genes. Validation using qRT-PCR also showed a consistent alteration of DHCR24 and MVK. Oxidative stress leads to the production of ROS which can attack lipid membrane constituents such as unsaturated phospholipids, glycolipids, and cholesterol, resulting in cellular dysfunction and cell death (Girotti 1998). Studies have reported that plasma membrane compartments rich in cholesterol may participate in signal transduction pathways activated upon oxidative stress, and thus enhance pro survival pathways, while cholesterol depletion appears to increase apoptosis in the oxidative stress-induced cells (Yang, Oo and Rizzo 2006). During oxidative stress, the expression of genes involved in lipid and cholesterol homeostasis, was shown to be activated by caspase cleavage (Yokoyama, Wang, Briggs et al. 1993). It has been reported that increased cholesterol content in cells concomitant to enhanced antioxidant capacity, made them less susceptible to oxidative stress (Kolanjiappan, Ramachandran and Manoharan 2003). These observations have led to the hypothesis that cholesterol is required as protection to the cells during oxidative damage to maintain plasma membrane integrity (Di Stasi, Vallacchi, Campi et al. 2005). 
683 MVK encodes for mevalonate kinase which phosphorylates mevalonate to mevalonate 5684 phosphate in the cholesterol biosynthetic pathway. Apart from cholesterol as the end-product, the 685 pathway is also responsible in synthesising several non-sterol isoprenes such as ubiquinone-10 or 686 also known as coenzyme Q10 (CoQ10) (Goldstein and Brown 1990). Studies have reported the 687 ability of CoQ10 to act as hydrophilic antioxidants and to protect biological membrane against 688 lipid peroxidation (Ernster and Forsmark-Andree 1993). In fact, ubiquinol-10 was reported to be 689 more efficient in preventing peroxidative damage to LDL than the well-known antioxidants 690 lycopene, beta-carotene, or alpha-tocopherol (Stocker, Bowry and Frei 1991). The up-regulation 691 of $M V K$ in this study could have led to the synthesis of lipid-soluble CoQ10 that might have 692 contributed to the lipid peroxidation inhibitory effect of the antioxidant-rich leaf extract of $T$. 693 indica.

694

695 The antioxidant-rich leaf extract of $T$. indica also significantly regulated the expression of 696 DHCR24 that encodes for 24-dehydrocholesterol reductase (DHCR24), the enzyme that 697 catalyzes the reduction of delta-24 double bond of sterol intermediates during cholesterol 698 biosynthesis (Waterham, Koster, Romeijn et al. 2001). DHCR24 has been shown to modulate 699 membrane cholesterol levels and lipid raft formation (Crameri, Biondi, Kuehnle et al. 2006). 700 Lipid rafts are cholesterol-rich microenvironments on the cell surface. They are required for cell 701 functions, including directed mobility and capping of membrane proteins, receptor-mediated 702 signalling, entry and exit of pathogens and membrane trafficking (Simons and Toomre 2000). DHCR24 has been reported to act as antioxidants via two mechanisms; the first through a 704 cholesterol-dependent manner (Kuehnle, Crameri, Kalin et al. 2008), possibly involving pro 
705

706

707

708

709

710

711

712

713

714

715

716

717

718

719

720

721

722

723

724

725

726

727

3

survival factors such as Akt and the second through direct scavenging of $\mathrm{H}_{2} \mathrm{O}_{2}(\mathrm{Lu}$, Kambe, Cao et al. 2008). DHCR24 was originally known as Seladin-1 gene (Selective Alzheimer's Disease Indicator-1) as its expression was initially discovered to be down-regulated in regions of the brain vulnerable to Alzheimer's disease (AD) (Iivonen, Hiltunen, Alafuzoff et al. 2002). Amyloid- $\beta$ (A $\beta$ ) peptide accumulation in the central nervous system underlies the pathological process in AD. Pharmacological enhancement of DHCR24 activity was reported to be protective against $\mathrm{A} \beta$ toxicity and oxidative stress-induced apoptosis in $\mathrm{AD}$ brain (Greeve, HermansBorgmeyer, Brellinger et al. 2000).

Lanosterol synthase $(L S S)$ catalyzes the cyclization of $(\mathrm{S})$-2,3-oxidosqualene to form lanosterol during sterol biosynthesis (Ausubel, Brent, E. et al. 1999). Oxidative stress has been reported to increase the level of lanosterol in mitochondria and several other intracellular compartments of macrophages, suggesting that this sterol metabolite may be part of a global cellular response to stress (Andreyev, Fahy, Guan et al. 2010).

More recently, defects in regulation of sterol metabolism has also been implicated in Parkinson's disease (PD). Lim et al, in 2012 reported that lanosterol showed neuroprotective effect in dopaminergic neurons in various models of PD (Lim, Jackson-Lewis, Wong et al. 2012). From this study, it is speculated that the leaf extract of $T$. indica may provide antioxidative protection against ROS-induced oxidative damage that can lead to AD and PD for instance, by regulating the expression of $D H C R 24, M V K$ and $L S S$ genes of the cholesterol biosynthesis superpathway. Studies reported the neuroprotective effects of citrus (Hwang et al., 2012) and blackcurrant (Vepsäläinen et al., 2013) flavonoids against $A \beta$ neurotoxicity by up-regulating the expression of 
728

729

730

731

732

733

734

735

736

737

738

739

740

741

742

743

744

745

746

747

748

749

750

genes involved in cholesterol metabolic pathway including DHCR24 (Hwang et al., 2012).

Amongst the flavonoids are quercetin and myricetin. Hence, quercetin together with the other flavonoids detected in the leaf extract might possibly work by a similar mechanism.

The leaf extract of $T$. indica has been reported to have antimicrobial activities (Meléndez \& Capriles, 2006) against some common gram negative and gram positive bacteria namely E. coli (Melendez and Capriles 2006) and Burkholderia pseudomallei (Muthu, Nandakumar and Rao 2005). Polyphenols detected in the methanol leaf extract of $T$. indica were known to exhibit antioxidative potential and have many beneficial effects on human health. Previously, in addition to quercetin and epicatechin, other polyphenols including isorhamnetin, were also detected in the leaf extract of $T$. indica (Razali et al., 2012). Isorhamnetin and quercetin isolated from speckled alder (Alnus incana ssp. rugosa) and the leaf extract of Calotropis procera (Nenaah, 2013) were reported to possess antimicrobial activity against Gram-positive bacteria including Staphylococcus aureus and Gram-negative bacteria namely E. coli (Rashed et al., 2014). Therefore, isorhamnetin and quercetin may have contributed towards the reported antimicrobial properties of the antioxidant-rich leaf extract of $T$. indica, through direct action on the expression of antimicrobial response-related genes, IFNGR1, LEAP2, ANXA3 and MX1.

Interferon- $\gamma(\mathrm{IFN}-\gamma)$ is a key mediator of the host immune response, and the IFN- $\gamma$ receptor 1 subunit that was encoded by IFNGRI is essential for IFN- $\gamma$ binding and signalling (Bach, Aguet and Schreiber 1997). IFN- $\gamma$ induces the expression of various cytokines and chemokines during the course of viral infection, including HBV and HCV (Barber 2001), and thus induces the virus clearance by cellular innate responses to eliminate viruses (Korachi, Ceran, Adaleti et al. 2013). 
752 LEAP2 codes for liver-expressed antimicrobial peptide-2 (LEAP-2), which significantly shares

753 structural characteristics with antimicrobial peptides such as defensins and LEAP-1/hepcidin.

754 LEAP-2 is the second blood-derived peptide that is expressed predominantly in the liver and 755 exhibits antimicrobial activity. As the first blood-derived antimicrobial peptide from the liver, 756 LEAP-1/hepcidin (Krause et al. 2000; Park et al. 2001) has been reported to be involved in iron 757 homeostasis (Nicolas et al. 2001; Pigeon et al. 2001). These important physiological functions 758 might be possible for LEAP-2 as well. A previous study has shown that LEAP-2 displayed dose759 dependent antimicrobial activity against numerous Gram-positive bacteria and yeasts namely $S$. 760 cerevisiae and B. subtilis (Krause, Sillard, Kleemeier et al. 2003). In fact, a study by Howard et 761 al. in 2010 elucidated a role for this peptide in protecting HepG2 cells from injury and/or stress 762 (Howard, Townes, Milona et al. 2010).

763

764 Myxovirus resistance protein (MX) encoded by $M X 1$ plays a major role in IFN-induced host 765 defense. MX, once induced by IFN- $\alpha$ and $\beta$, blocks viral replication cycle at an early stage thus 766 provided an early antiviral innate immunity (Haller, Frese and Kochs 1998). Human MX 767 demonstrates a wide antiviral spectrum of activities against orthomyxo viruses including 768 influenza viruses, rhabdoviruses, Bunyaviridae and paramyxoviride (Frese, Kochs, Feldmann et 769 al. 1996; Tumpey, Szretter, Van Hoeven et al. 2007). Numerous experiments have also indicated 770 that recovery from virus infection in humans requires a functional MX defense system (Staeheli, 771 Haller, Boll et al. 1986; Moritoh, Yamauchi, Asano et al. 2009).

773 Annexins are a family of proteins that binds to phospholipids and membranes in a calcium- 
774 dependent manner and may link calcium signalling to membrane functions (Larsson, Majeed,

775 Ernst et al. 1997). ANXA3 also exhibited important roles in tumor development, metastasis and

776 drug resistance (Wu, Liu, Guo et al. 2013) and showed up-regulated expression in many active

777 cancers (Hayes and Moss 2004; Mussunoor and Murray 2008). Furthermore, it has been shown

778 that $A N X A 3$ interacted with molecules of the S100 family of calcium binding molecules (Gerke

779 and Moss 2002). Members of this family are suggested to play an important role in psoriasis

780 pathogenesis and showed up-regulated expression in psoriatic lesional skin, thus suggesting its

781 pathogenic role in this disease (Koczan, Guthke, Thiesen et al. 2005).

782

783 Changes in the expression of a gene may not necessarily lead to alteration in the abundance of 784 the corresponding protein. However, in this study, it was evident that the alteration in gene 785 expression by HepG2 when exposed to the leaf extract was corroborated by changes in 786 abundance of the corresponding proteins. The antioxidant-rich leaf extract of $T$. indica appeared 787 to be able to alter the expression of proteins that are involved in the Coagulation System and the 788 Intrinsic Prothrombin Activation Pathway (KNG1, SERPINE1, FGG), Superpathway of 789 Cholesterol Biosynthesis (MVK), Immune protection/antimicrobial response (IFNGR1, LEAP2, ANXA3) and MX1) and Xenobiotic Metabolism Signaling (ALDH6A1, ADH6). Western blot analysis showed consistent pattern of expression of the SERPINE1 and IFNGR1 was detected 792 hence validating the ELISA and microarray data.

Conclusion 
796 The antioxidant-rich methanol leaf extract of $T$. indica extract showed protective effects in

797 HepG2 cells by inhibiting lipid peroxidation, enhancing the antioxidant enzyme activities and

798 suppressing the ROS production. The present study implies the potential of this plant as an

799 alternative source of a natural antioxidant agent and the promising therapeutic potential of the

800 leaves of $T$. indica. Inhibition of lipid peroxidation involved alteration in the expression of genes

801 and the encoded proteins which are responsible for the degradation of MDA and HNE. The

802 antioxidant-rich methanol leaf extract of $T$. indica extract also directly targeted the expression of

803 genes and the encoded proteins that are involved in the coagulation system and antimicrobial

804 response hence providing molecular evidence associated to the medicinal properties of the leaf 805 extract.

806

807 Acknowledgement

808 We would like to thank Siah Eng Tian and Teng Loong Hung from Research Instruments

809 Malaysia for their technical expertise.

810

811

812

813

814

815

816

817

818 
820

821

822

823

824

825

826

827

828

829

830

831

832

833

834

835

836

837

838

839

840

841

842

843

844

845

846

847

848

849

850

851

852

853

854

855

856

857

858

859

860

861

Andreyev, A. Y., E. Fahy, Z. Guan, S. Kelly, X. Li, J. G. McDonald, S. Milne, D. Myers, H. Park, A. Ryan, B. M. Thompson, E. Wang, Y. Zhao, H. A. Brown, A. H. Merrill, C. R. Raetz, D. W. Russell, S. Subramaniam and E. A. Dennis (2010). "Subcellular organelle lipidomics in TLR-4-activated macrophages." J Lipid Res 51(9): 2785-2797.

Ausubel, F. M., R. Brent, K. R. E., D. D. Moore, J. G. Seidman, J. A. Smith and K. Struhl (1999). Short Protocols in Molecular Biology:A Compendium of Methods from Current Protocols in Molecular Biology. New York, John Wiley and Sons.

Awah, M. F. and W. A. Verla (2010). "Antioxidant activity, nitric oxide scavenging activity and phenolic contents of Ocimum gratissimum leaf extract." J Med Plants Res 4(24): 24792487.

Bach, E. A., M. Aguet and R. D. Schreiber (1997). "The IFN gamma receptor: a paradigm for cytokine receptor signaling." Annu Rev Immunol 15: 563-591.

Baglin, T. P., R. W. Carrell, F. C. Church, C. T. Esmon and J. A. Huntington (2002). "Crystal structures of native and thrombin-complexed heparin cofactor II reveal a multistep allosteric mechanism." Proc Natl Acad Sci U S A 99(17): 11079-11084.

Bolliger, D., K. Gorlinger and K. A. Tanaka (2010). "Pathophysiology and treatment of coagulopathy in massive hemorrhage and hemodilution." Anesthesiology 113(5): 12051219.

Brattin, W. J., E. A. Glende, Jr. and R. O. Recknagel (1985). "Pathological mechanisms in carbon tetrachloride hepatotoxicity." J Free Radic Biol Med 1(1): 27-38.

Chen, X., Z. Zhong, Z. Xu, L. Chen and Y. Wang (2011). "No protective effect of curcumin on hydrogen peroxide-induced cytotoxicity in HepG2 cells." Pharmacol Rep 63(3): 724-732.

Covas, M. I., K. Nyyssonen, H. E. Poulsen, J. Kaikkonen, H. J. Zunft, H. Kiesewetter, A. Gaddi, R. de la Torre, J. Mursu, H. Baumler, S. Nascetti, J. T. Salonen, M. Fito, J. Virtanen, J. Marrugat and E. S. Group (2006). "The effect of polyphenols in olive oil on heart disease risk factors: a randomized trial." Ann Intern Med 145(5): 333-341.

Crameri, A., E. Biondi, K. Kuehnle, D. Lutjohann, K. M. Thelen, S. Perga, C. G. Dotti, R. M. Nitsch, M. D. Ledesma and M. H. Mohajeri (2006). "The role of seladin-1/DHCR24 in cholesterol biosynthesis, APP processing and Abeta generation in vivo." EMBO J 25(2): 432-443.

Denizot, F. and R. Lang (1986). "Rapid colorimetric assay for cell growth and survival. Modifications to the tetrazolium dye procedure giving improved sensitivity and reliability." J Immunol Methods 89(2): 271-277.

Di Stasi, D., V. Vallacchi, V. Campi, T. Ranzani, M. Daniotti, E. Chiodini, S. Fiorentini, I. Greeve, A. Prinetti, L. Rivoltini, M. A. Pierotti and M. Rodolfo (2005). "DHCR24 gene expression is upregulated in melanoma metastases and associated to resistance to oxidative stress-induced apoptosis." Int J Cancer 115(2): 224-230.

Ernster, L. and P. Forsmark-Andree (1993). "Ubiquinol: an endogenous antioxidant in aerobic organisms." Clin Investig 71(8 Suppl): S60-65.

Escalona-Arranz J.C, J. Garcia-Diaz, R. Perez-Rosés, J. De la Vega, J. Rodríguez-Amado, H. J. Morris-Quevedo (2014). "Effect of Tamarindus indica L. leaves' fluid extract on human blood cells. " Nat Prod Res 28(18): 1485-1488. 
862 Frese, M., G. Kochs, H. Feldmann, C. Hertkorn and O. Haller (1996). "Inhibition of 863 bunyaviruses, phleboviruses, and hantaviruses by human MxA protein." J Virol 70(2): 915-923.

866

Gerke, V. and S. E. Moss (2002). "Annexins: from structure to function." Physiol Rev 82(2): 331-371.

Ghoneim, A. I. and O. A. Eldahshan (2012). "Anti-apoptotic effects of tamarind leaves against ethanol-induced rat liver injury." J Pharm Pharmacol 64(3): 430-438.

869 Girotti, A. W. (1998). "Lipid hydroperoxide generation, turnover, and effector action in biological systems." J Lipid Res 39(8): 1529-1542.

Goldstein, J. L. and M. S. Brown (1990). "Regulation of the mevalonate pathway." Nature 343(6257): 425-430.

Greeve, I., I. Hermans-Borgmeyer, C. Brellinger, D. Kasper, T. Gomez-Isla, C. Behl, B. Levkau and R. M. Nitsch (2000). "The human DIMINUTO/DWARF1 homolog seladin-1 confers resistance to Alzheimer's disease-associated neurodegeneration and oxidative stress." J Neurosci 20(19): 7345-7352.

Gu, L., S. E. House, X. Wu, B. Ou and R. L. Prior (2006). "Procyanidin and catechin contents and antioxidant capacity of cocoa and chocolate products." J Agric Food Chem 54(11): 4057-4061.

Guglielmone, H. A., A. M. Agnese, S. C. Nunez Montoya and J. L. Cabrera (2002). "Anticoagulant effect and action mechanism of sulphated flavonoids from Flaveria bidentis." Thromb Res 105(2): 183-188.

Haller, O., M. Frese and G. Kochs (1998). "Mx proteins: mediators of innate resistance to RNA viruses." Rev Sci Tech 17(1): 220-230.

Halliwell, B. (1994). "Free radicals, antioxidants, and human disease: curiosity, cause, or consequence?" Lancet 344(8924): 721-724.

Hansen, M. B., S. E. Nielsen and K. Berg (1989). "Re-examination and further development of a precise and rapid dye method for measuring cell growth/cell kill." J Immunol Methods 119(2): 203-210.

Hayes, M. J. and S. E. Moss (2004). "Annexins and disease." Biochem Biophys Res Commun 322(4): 1166-1170.

He, L., C. P. Vicente, R. J. Westrick, D. T. Eitzman and D. M. Tollefsen (2002). "Heparin cofactor II inhibits arterial thrombosis after endothelial injury." J Clin Invest 109(2): 213219.

He, S., M. Blomback, G. Jacobsson Ekman and U. Hedner (2003). "The role of recombinant factor VIIa (FVIIa) in fibrin structure in the absence of FVIII/FIX." J Thromb Haemost 1(6): 1215-1219.

Higdon, J. V. and B. Frei (2003). "Tea Catechins and Polyphenols: Health Effects, Metabolism, and Antioxidant Functions." Crit Rev Food Sci Nutr 43(1): 89-143.

Howard, A., C. Townes, P. Milona, C. J. Nile, G. Michailidis and J. Hall (2010). "Expression and functional analyses of liver expressed antimicrobial peptide-2 (LEAP-2) variant forms in human tissues." Cell Immunol 261(2): 128-133.

Iivonen, S., M. Hiltunen, I. Alafuzoff, A. Mannermaa, P. Kerokoski, J. Puolivali, A. Salminen, S. Helisalmi and H. Soininen (2002). "Seladin-1 transcription is linked to neuronal degeneration in Alzheimer's disease." Neuroscience 113(2): 301-310. 
Imam, M. U. and M. Ismail (2013). Nutrigenomic effects of germinated brown rice and its bioactives on hepatic gluconeogenic genes in type 2 diabetic rats and HEPG2 cells. Mol Nut Food Res 57(3): 401-411.

Imam, S., I. Azhar, M. M. Hasan, M. S. Ali and S. W. Ahmed (2007). "Two triterpenes lupanone and lupeol isolated and identified from Tamarindus indica linn." Pak J Pharm Sci 20(2): 125-127.

Inal, M. E., G. Kanbak and E. Sunal (2001). "Antioxidant enzyme activities and malondialdehyde levels related to aging." Clin Chim Acta 305(1-2): 75-80.

Khaleghi, S., A. A. Aziz, N. Razali and S. M. Junit (2011). Microarray analysis revealed different gene expression patterns in HepG2 cells treated with low and high concentrations of the extracts of Anacardium occidentale shoots. Genes Nutr 6(4): 413427.

Knasmüller, S., V. Mersch-Sundermann, S. Kevekordes, F. Darroudi, W. W. Huber, C. Hoelzl, J. Bichler, and B. J. Majer (2004). "Use of human-derived liver cell lines for the detection of environmental and dietary genotoxicants; current state of knowledge." Toxicology 198(1): 315-328.

Koczan, D., R. Guthke, H. J. Thiesen, S. M. Ibrahim, G. Kundt, H. Krentz, G. Gross and M. Kunz (2005). "Gene expression profiling of peripheral blood mononuclear leukocytes from psoriasis patients identifies new immune regulatory molecules." Eur J Dermatol 15(4): 251-257.

Kolanjiappan, K., C. R. Ramachandran and S. Manoharan (2003). "Biochemical changes in tumor tissues of oral cancer patients." Clin Biochem 36(1): 61-65.

Korachi, M., N. Ceran, R. Adaleti, A. Nigdelioglu and M. Sokmen (2013). "An association study of functional polymorphic genes IRF-1, IFNGR-1, and IFN-gamma with disease progression, aspartate aminotransferase, alanine aminotransferase, and viral load in chronic hepatitis B and C." Int J Infect Dis 17(1): e44-49.

Krause, A., R. Sillard, B. Kleemeier, E. Kluver, E. Maronde, J. R. Conejo-Garcia, W. G. Forssmann, P. Schulz-Knappe, M. C. Nehls, F. Wattler, S. Wattler and K. Adermann (2003). "Isolation and biochemical characterization of LEAP-2, a novel blood peptide expressed in the liver." Protein Sci 12(1): 143-152.

Kuehnle, K., A. Crameri, R. E. Kalin, P. Luciani, S. Benvenuti, A. Peri, F. Ratti, M. Rodolfo, L. Kulic, F. L. Heppner, R. M. Nitsch and M. H. Mohajeri (2008). "Prosurvival effect of DHCR24/Seladin-1 in acute and chronic responses to oxidative stress." Mol Cell Biol 28(2): 539-550.

Lang, T., K. Johanning, H. Metzler, S. Piepenbrock, C. Solomon, N. Rahe-Meyer and K. A. Tanaka (2009). "The effects of fibrinogen levels on thromboelastometric variables in the presence of thrombocytopenia." Anesth Analg 108(3): 751-758.

Larsson, M., M. Majeed, J. D. Ernst, K. E. Magnusson, O. Stendahl and U. Forsum (1997). "Role of annexins in endocytosis of antigens in immature human dendritic cells." Immunology 92(4): 501-511.

Le Marchand, L. (2002). "Cancer preventive effects of flavonoids--a review." Biomed Pharmacother 56(6): 296-301.

Levy, J. H., F. Szlam, K. A. Tanaka and R. M. Sniecienski (2012). "Fibrinogen and hemostasis: a primary hemostatic target for the management of acquired bleeding." Anesth Analg 114(2): 261-274. 
Lim, L., V. Jackson-Lewis, L. C. Wong, G. H. Shui, A. X. Goh, S. Kesavapany, A. M. Jenner, M. Fivaz, S. Przedborski and M. R. Wenk (2012). "Lanosterol induces mitochondrial uncoupling and protects dopaminergic neurons from cell death in a model for Parkinson's disease." Cell Death Differ 19(3): 416-427.

Lu, X., F. Kambe, X. Cao, Y. Kozaki, T. Kaji, T. Ishii and H. Seo (2008). "3betaHydroxysteroid-delta24 reductase is a hydrogen peroxide scavenger, protecting cells from oxidative stress-induced apoptosis." Endocrinology 149(7): 3267-3273.

Marabini, L., S. Frigerio, E. Chiesara and S. Radice (2006). "Toxicity evaluation of surface water treated with different disinfectants in HepG2 cells." Water Res 40(2): 267-272.

Melendez, P. A. and V. A. Capriles (2006). "Antibacterial properties of tropical plants from Puerto Rico." Phytomedicine 13(4): 272-276.

Mersch-Sundermann, V., S. Knasmüller, X. J. Wu, F. Darroudi, and F. Kassie (2004). Use of a human-derived liver cell line for the detection of cytoprotective, antigenotoxic and cogenotoxic agents. Toxicology 198(1): 329-340

Moritoh, K., H. Yamauchi, A. Asano, K. Yoshii, H. Kariwa, I. Takashima, N. Isoda, Y. Sakoda, H. Kida, N. Sasaki and T. Agui (2009). "Generation of congenic mouse strains by introducing the virus-resistant genes, $\mathrm{Mx} 1$ and Oas1b, of feral mouse-derived inbred strain MSM/Ms into the common strain C57BL/6J." Jpn J Vet Res 57(2): 89-99.

Mosesson, M. W. (2005). "Fibrinogen and fibrin structure and functions." J Thromb Haemost 3(8): 1894-1904.

Mosmann, T. (1983). "Rapid colorimetric assay for cellular growth and survival: application to proliferation and cytotoxicity assays." J Immunol Methods 65(1-2): 55-63.

Mussunoor, S. and G. I. Murray (2008). "The role of annexins in tumour development and progression." J Pathol 216(2): 131-140.

Muthu, S. E., S. Nandakumar and U. A. Rao (2005). "The effect of methanolic extract of Tamarindus indica Linn. on the growth of clinical isolates of Burkholderia pseudomallei." Indian J Med Res 122(6): 525-528.

Oh, S. H. and S. C. Lim (2006). "A rapid and transient ROS generation by cadmium triggers apoptosis via caspase-dependent pathway in HepG2 cells and this is inhibited through Nacetylcysteine-mediated catalase upregulation." Toxicol Appl Pharmacol 212(3): 212223.

Razali, N., A. A. Aziz and S. M. Junit (2010). "Gene expression profiles in human HepG2 cells treated with extracts of the Tamarindus indica fruit pulp." Genes Nutr 5(4): 331-341.

Razali, N., S. Mat-Junit, A. F. Abdul-Muthalib, S. Subramaniam and A. Abdul-Aziz (2012). "Effects of various solvents on the extraction of antioxidant phenolics from the leaves, seeds, veins and skins of Tamarindus indica L." Food Chem 131(2): 441-448.

Reaven, P. D., A. Khouw, W. F. Beltz, S. Parthasarathy and J. L. Witztum (1993). "Effect of dietary antioxidant combinations in humans. Protection of LDL by vitamin E but not by beta-carotene." Arterioscler Thromb 13(4): 590-600.

Rigoulet, M., E. D. Yoboue and A. Devin (2011). "Mitochondrial ROS generation and its regulation: mechanisms involved in $\mathrm{H}(2) \mathrm{O}(2)$ signaling." Antioxid Redox Signal 14(3): 459-468.

Saez-Rodriguez, J., L. G. Alexopoulos, M. Zhang, M. K. Morris, D. A. Lauffenburger and P. K. Sorger (2011). Comparing signaling networks between normal and transformed hepatocytes using discrete logical models. Cancer Res 71(16): 5400-5411. 
1000

1001

1002

1003

1004

1005

1006

1007

1008

1009

1010

1011

1012

1013

1014

1015

1016

1017

1018

1019

1020

1021

1022

1023

1024

1025

1026

1027

1028

1029

1030

1031

1032

1033

1034

1035

1036

1037

1038

1039

1040

Sang, S., S. Tian, H. Wang, R. E. Stark, R. T. Rosen, C. S. Yang and C. T. Ho (2003). "Chemical studies of the antioxidant mechanism of tea catechins: radical reaction products of epicatechin with peroxyl radicals." Bioorg Med Chem 11(16): 3371-3378.

Siddiqi, F. A., J. Tepler and G. A. Fantini (1997). "Acquired protein S and antithrombin III deficiency caused by nephrotic syndrome: an unusual cause of graft thrombosis." J Vasc Surg 25(3): 576-580.

Simons, K. and D. Toomre (2000). "Lipid rafts and signal transduction." Nat Rev Mol Cell Biol 1(1): 31-39.

Singh, B. N., S. Shankar and R. K. Srivastava (2011). "Green tea catechin, epigallocatechin-3gallate (EGCG): mechanisms, perspectives and clinical applications." Biochem Pharmacol 82(12): 1807-1821.

Singh, I., M. Mok, A. M. Christensen, A. H. Turner and J. A. Hawley (2008). "The effects of polyphenols in olive leaves on platelet function." Nutr Metab Cardiovasc Dis 18(2): 127132.

Sreelekha, T. T., T. Vijayakumar, R. Ankanthil, K. K. Vijayan and M. K. Nair (1993). "Immunomodulatory effects of a polysaccharide from Tamarindus indica." Anticancer Drugs 4(2): 209-212.

Staeheli, P., O. Haller, W. Boll, J. Lindenmann and C. Weissmann (1986). "Mx protein: constitutive expression in 3T3 cells transformed with cloned Mx cDNA confers selective resistance to influenza virus." Cell 44(1): 147-158.

Stocker, R., V. W. Bowry and B. Frei (1991). "Ubiquinol-10 protects human low density lipoprotein more efficiently against lipid peroxidation than does alpha-tocopherol." Proc Natl Acad Sci U S A 88(5): 1646-1650.

Sudhahar, V., S. A. Kumar, P. Varalakshmi and R. Sundarapandiyan (2007). "Mitigating role of lupeol and lupeol linoleate on hepatic lipemic-oxidative injury and lipoprotein peroxidation in experimental hypercholesterolemia." Mol Cell Biochem 295(1-2): 189198.

Tanaka, K. A., N. S. Key and J. H. Levy (2009). "Blood coagulation: hemostasis and thrombin regulation." Anesth Analg 108(5): 1433-1446.

Thangapazham, R. L., N. Passi and R. K. Maheshwari (2007). "Green tea polyphenol and epigallocatechin gallate induce apoptosis and inhibit invasion in human breast cancer cells." Cancer Biol Ther 6(12): 1938-1943.

Tollefsen, D. M., C. A. Pestka and W. J. Monafo (1983). "Activation of heparin cofactor II by dermatan sulfate." J Biol Chem 258(11): 6713-6716.

Tumpey, T. M., K. J. Szretter, N. Van Hoeven, J. M. Katz, G. Kochs, O. Haller, A. Garcia-Sastre and P. Staeheli (2007). "The Mx1 gene protects mice against the pandemic 1918 and highly lethal human H5N1 influenza viruses." J Virol 81(19): 10818-10821.

Valko, M., C. J. Rhodes, J. Moncol, M. Izakovic and M. Mazur (2006). "Free radicals, metals and antioxidants in oxidative stress-induced cancer." Chem Biol Interact 160(1): 1-40.

Waterham, H. R., J. Koster, G. J. Romeijn, R. C. Hennekam, P. Vreken, H. C. Andersson, D. R. FitzPatrick, R. I. Kelley and R. J. Wanders (2001). "Mutations in the 3beta-hydroxysterol Delta24-reductase gene cause desmosterolosis, an autosomal recessive disorder of cholesterol biosynthesis." Am J Hum Genet 69(4): 685-694.

Wu, N., S. Liu, C. Guo, Z. Hou and M. Z. Sun (2013). "The role of annexin A3 playing in cancers." Clin Transl Oncol 15(2): 106-110. 
1041 Yang, B., T. N. Oo and V. Rizzo (2006). "Lipid rafts mediate $\mathrm{H}_{2} \mathrm{O}_{2}$ prosurvival effects in 1042 cultured endothelial cells." FASEB J 20(9): 1501-1503.

1043 Yokoyama, C., X. Wang, M. R. Briggs, A. Admon, J. Wu, X. Hua, J. L. Goldstein and M. S. 1044 Brown (1993). "SREBP-1, a basic-helix-loop-helix-leucine zipper protein that controls 1045 transcription of the low density lipoprotein receptor gene." Cell 75(1): 187-197. 
1047 Figure-legend:

1048 Figure 1 (A-B): Analyses of lipid peroxidation, antioxidant enzymes and reactive oxygen species

1049 (ROS) in untreated, untreated $+\mathrm{H}_{2} \mathrm{O}_{2}$-induced and leaf-pre-treated $+\mathrm{H}_{2} \mathrm{O}_{2}$-induced HepG2 cells.

1050 The effects of the leaf extract on lipid peroxidation, measured as MDA levels (A) and 4-HNE

1051 protein adduct level (B) in HepG2 cells. Results for MDA levels were expressed as nmol MDA

1052 equivalents/mg of protein while 4-HNE levels were expressed as nmol 4-HNE adduct/mg of 1053 protein. MDA- malondialdehyde; 4-HNE - 4-hydroxynonenal

1054

1055 Figure 1(C-E): Superoxide dismutase (C), catalase (D) and glutathione peroxidase (E) activities 1056 were determined using commercial assay kits (Cayman Chemicals).

Figure 1F: ROS production in HepG2 cells was measured using fluorescence multi-detection microplate reader and the results were expressed as Relative Fluorescence Unit (RFU). Values with different lower case letters are significantly different $(\mathrm{p}<0.05)$.

1061

1062

Figure 2 (A-C): Image-based ROS measurement captured by fluorescence microscopy in HepG2 cells; (A): Untreated and unchallenged HepG2, (B): Untreated and $\mathrm{H}_{2} \mathrm{O}_{2}$-challenged HepG2 and (C): Leaf-pre-treated and $\mathrm{H}_{2} \mathrm{O}_{2}$-challenged HepG2.

1065

Figure 3A: A Principal Component Analysis (PCA) plot generated using Partek software of

1067 HepG2 cells grown in presence or absence of the methanol leaf extract of $T$. indica. (Data are 1068 clustered based on three biological replicates $(n=3)$ of control and treated samples. Arrays for the 
1069

1070

1071

1072

1073

1074

1075

1076

1077

1078

1079

1080

1081

1082

1083

1084

1085

1086

1087

1088

1089

1090

1091

untreated group are in blue and those for the treated group are in green. Each ball represents a sample.

Figure 3B: Hierarchical clustering of highly significant genes that are associated to different pathways generated by Genesis software. The gene expression was regulated in response to the treatment with leaf extract on HepG2 cells. The regulation pattern was differentiated with 2 colours; green for down regulation and red for up regulation. The clustering was generated using Genesis software.

Figure 4: Validation of the microarray data using qRT-PCR. The bar chart shows the gene expression patterns (presented as fold change) of selected significantly regulated genes calculated using qRT-PCR and microarray analysis. The down-regulated genes selected were CYP24A1, ANXA3 and AREG, while the up-regulated genes were LEAP2,FGA,FGG, SERPINE1, IFNGR1, MVK, DHCR24, ALDH6A1 and ADH6. All qRT-PCR data were normalized to that of $G A P D H$, a housekeeping gene.

Figure 5A: IPA graphical representation of the molecular relationships between the significantly regulated genes to the predicted canonical pathways in response to the leaf treatment in HepG2 cells. The network is displayed graphically as nodes (genes) and edges (the biological relationships between the nodes). Nodes in red indicate up-regulated genes while those in green represent down-regulated genes. Various shapes of the nodes represent functional class of the proteins. Edges are displayed with various labels that describe the nature of the relationship between the nodes. Name of genes with their corresponding abbreviations are as follows: ADH6, 
1092 Alcohol dehydrogenase 6; ALDH6A1, Aldehyde dehydrogenase 6 family, member A1;

1093 ALDH9A1, Aldehyde dehydrogenase 9 family, member A1; ANXA3, Annexin A3; CYP24A1,

1094 Cytochrome P450, family 24, subfamily A, polypeptide 1; DHCR24, 24-dehydrocholesterol

1095 reductase; $E P H X 1$, Epoxide hydrolase 1; $F G A$, Fibrinogen alpha chain; $F G G$, Fibrinogen gamma

1096 chain; GSTM4, Glutathione S-transferase mu 4; IFNGR1, Interferon gamma receptor 1; KNG1,

1097 Kininogen 1; LEAP2, Liver-expressed antimicrobial peptide; LSS, Lanosterol synthase; MVK,

1098 Mevalonate kinase; MX1, Myxovirus resistance 1; SERPINC1, Serpin peptidase inhibitor, clade

1099 C (antithrombin), member 1; SERPIND1, Serpin peptidase inhibitor, clade D (heparin cofactor),

1100 member 1, SERPINE1, Serpin peptidase inhibitor, clade E (Nexin, Plasminogen activator

1101 inhibitor, type 1), member 1; TM7SF2, Transmembrane 7 superfamily member 2.

1102

1103 Figure 5B: IPA graphical representation showing the effect of significantly regulated genes,

1104 ALDH6A1, ALDH6 and GSTM4 in the detoxification process of 4-HNE and MDA. This figure

1105 demonstrates that the three genes are involved in the xenobiotic metabolism signaling pathway

1106 as on one of the top canonical pathway generated by IPA. The process is displayed graphically as

1107 nodes (genes) and edges (the biological relationships between the nodes). Nodes in red indicate

1108 up-regulated genes. Various shapes of the nodes represent functional class of the proteins. Edges

1109 are displayed with various labels that describe the nature of the relationship between the nodes.

1110

1111 Figure 5C: IPA graphical representation of the molecular relationships between KNG1,

1112 SERPINE1, SERPINC1, SERPIND1 and Fibrinogen that are involved in "Coagulation System",

1113 the top predicted canonical pathway in HepG2 cells affected by the methanol leaf extract of $T$.

1114 indica. The network is displayed graphically as nodes (genes) and edges (the biological 
1115 relationships between the nodes). Nodes in red indicate up-regulated genes. Various shapes of

1116 the nodes represent functional class of the proteins. Edges are displayed with various labels that

1117 describe the nature of the relationship between the nodes. Name of genes/proteins with their

1118 corresponding abbreviations are as follows: $A 2 M$, Alpha-2-macroglobulin; $B D K$, Bradykinin;

$1119 B D K R$, Bradykinin receptor; F2, Coagulation factor II (thrombin); F2a, Coagulation factor IIa

1120 (thrombin); F2R, Coagulation factor II receptor; F3, Coagulation factor III (thromboplastin,

1121 tissue factor); F5a, Coagulation factor V (proaccelerin, labile factor); F7, Coagulation factor VII

1122 (serum prothrombin conversion accelerator); F7a, Coagulation factor VIIa (serum prothrombin

1123 conversion accelerator); F8, Coagulation factor VIII (procoagulant component); F8a,

1124 Coagulation factor VIIIa (procoagulant component); F9, Coagulation factor IX; F9a,

1125 Coagulation factor IXa; F10, Coagulation factor X; F10a, Coagulation factor Xa; F11,

1126 Coagulation factor XI; F11a, Coagulation factor XIa; F12, Coagulation factor XII (Hageman

1127 factor); F12a, Coagulation factor XIIa (Hageman factor); F13- Coagulation factor XIII; F13a,

1128 Coagulation factor XIIIa; KLKB1a, Kallikrein B plasma 1a; PLG, Plasminogen; SERPINA1,

1129 Serpin peptidase inhibitor, clade A, member 1; SERPINA5, Serpin peptidase inhibitor, clade A,

1130 member 5; SERPINF2, Serpin peptidase inhibitor, clade F, member 2; TFPI, Tissue factor

1131 pathway inhibitor; THBD, Thrombomodulin; TPA, Tissue plasminogen activator; UPA,

1132 Urokinase plasminogen activator; UPAR, Urokinase plasminogen activator receptor; vWF, von

1133 Willebrand factor.

1134

1135 Figure 6A: Enzyme-Linked Immunosorbent Assay (ELISA) analyses of the human IFNGR1, 1136 LEAP2, SERPINE1, ANXA3, KNG1, MX1, FGG, MVK, ALDH6A1 and ADH6 antibodies 
1137 level in the untreated and leaf-treated HepG2 cells. ELISA analyses were done according to

1138 manufacturer's protocols (Cloud-clone, Texas, US and Cusabio Biotech, Wuhan, China).

1139 Bars not sharing the same superscript letter indicate significant difference at $\mathrm{p}<0.05$

1140

1141 Figure 6B: Up regulation of IFNGR1 (a) and SERPINE1 (b) after treatment with $\mathrm{IC}_{20}$ 1142 concentration of the leaf extract for 24 hours. Protein levels were measured with specific 1143 antibodies by western blot analysis; $\beta$-actin was the loading control. Untreated cells were used as 1144 control. The experiments were repeated in triplicates and the representative blot was shown.

1145 Bars not sharing the same superscript letter indicate significant difference at $p<0.05$

1146

1147 
Table $\mathbf{1}_{\text {(on next page) }}$

list of selected significantly regulated genes

Table 1: A list of highly significant up-regulated and down-regulated genes in HepG2 cells treated with the methanol leaf extract of $T$. indica generated using GO analyses from Partek Genomics Suite software. The data are presented with details of the GenBank accession number, biological functions, name of the gene and its respective protein and fold change difference between treated and untreated cells. Negative values indicate down-regulation of the genes. 
1 Table 1: A list of highly significant up-regulated and down-regulated genes in HepG2 cells 2 treated with the methanol leaf extract of $T$. indica generated using GO analyses from Partek 3 Genomics Suite software. The data are presented with details of the GenBank accession number, 4 biological functions, name of the gene and its respective protein and fold change difference 5 between treated and untreated cells. Negative values indicate down-regulation of the genes.

6

\begin{tabular}{|c|c|c|}
\hline GenBank ID & Protein (Gene name) & $\begin{array}{c}\text { Fold change } \\
\text { (leaf-treated vs. } \\
\text { untreated) }\end{array}$ \\
\hline \multicolumn{3}{|c|}{$\begin{array}{l}\text { Hematological System } \\
\text { Development and Function }\end{array}$} \\
\hline NM_000508 & Fibrinogen alpha chain $(F G A)$ & 3.03 \\
\hline NM_000602 & $\begin{array}{l}\text { Serpin peptidase inhibitor, clade E, member } 1 \\
\text { (SERPINE1) }\end{array}$ & 2.75 \\
\hline NM_021870 & Fibrinogen gamma chain $(F G G)$ & 2.39 \\
\hline NM_000488 & $\begin{array}{l}\text { Serpin peptidase inhibitor, clade } \mathrm{C} \text {, member } 1 \\
\text { (SERPPINC1) }\end{array}$ & 2.14 \\
\hline NM_000893 & Kininogen $1(K N G l)$ & 1.84 \\
\hline NM_000185 & $\begin{array}{l}\text { Serpin peptidase inhibitor, clade } \mathrm{D} \text {, member } 1 \\
\text { (SERPINDI) }\end{array}$ & 1.58 \\
\hline \multicolumn{3}{|c|}{$\begin{array}{l}\text { Lipid Metabolic and } \\
\text { Transport Process }\end{array}$} \\
\hline NM_001713 & Betaine-homocysteine S-methyltransferase (BHMT) & 2.65 \\
\hline NM_174936 & $\begin{array}{l}\text { Proprotein convertase subtilisin/kexin type } 9 \\
(\text { PCSK } 9)\end{array}$ & 2.39 \\
\hline NM_025225 & $\begin{array}{l}\text { Patatin-like phospholipase domain containing } 3 \\
(P N P L A 3)\end{array}$ & 2.31 \\
\hline NM_005063 & $\begin{array}{l}\text { Stearoyl-CoA desaturase (delta-9-desaturase) } \\
(S C D)\end{array}$ & 2.17 \\
\hline NM_001025195 & Carboxylesterase 1 (CESI) & 2.13 \\
\hline
\end{tabular}


NM_014762

NM_001964

NM_019101

NM_001045

NM_005116

NM_012079

NM_006214

NM_001102402

NM_001710

NM_001122

Carbohydrate Metabolic

Process

NM_000151

NM_001128127

NM_001146274

Regulation of Hormone

NM_001040

NM_000371

Inflammatory Response

NM_032562

NM_002960

NM_001562 24-dehydrocholesterol reductase (DHCR24)

1.91

Early growth response 1 (EGRl)

Apolipoprotein M (APOM)

1.80

Solute carrier family 6 (SLC6A4)

1.76

Solute carrier family 23 (SLC23A2)

1.71

Diacylglycerol O-acyltransferase homolog 1

1.68 (DGAT1)

Phytanoyl-CoA 2-hydroxylase $(P H Y H)$

Phosphatidylcholine transfer protein (PCTP)

Complement factor $\mathrm{B}(C F B)$

Perilipin 2 (PLIN2)

Glucose-6-phosphatase, catalytic subunit (G6PC)

Glycerol kinase $(G K)$

Transcription factor 7-like 2 (T-cell specific, HMGbox) (TCF7L2)

$-1.56$

Sex hormone-binding globulin $(S H B G)$

Transthyretin (TTR)

Phospholipase A2, group XIIB (PLA2G12B) 1.50

S100 calcium binding protein A3 (S100A3) $\quad-3.05$

Interleukin 18 (IL18) 
Defense Response to

Virus/Bacterium

NM_052971

NM_002462

NM_000416

NM_005139

Xenobiotic Metabolic

Process

NM_000120

NM_005589

NM_000850

NM_000696

NM_001102470

NM_000782

Immune Response

NM_004107
Liver expressed antimicrobial peptide 2 (LEAP2)

1.96

Myxovirus (influenza virus) resistance $1(M X 1)$

1.58

Interferon gamma receptor 1 (IFNGRl)

Annexin A3 (ANXA3)
Epoxide hydrolase $1(E P H X 1)$

Aldehyde dehydrogenase 6 family, member A1 (ALDH6A1)

Glutathione S-transferase mu 4 (GSTM4)

Aldehyde dehydrogenase 9 family, member A1 (ALDH9A1)

Alcohol dehydrogenase 6 (ADHO)

Cytochrome P450, family 24, subfamily A, polypeptide 1 (CYP24A1)

2.12

1.86

Fc fragment of IgG, receptor, transporter (FCGRT) 
Table 2 (on next page)

IPA analysis

Table 2: A summary of Ingenuity Pathway Analysis (IPA) showed the top networks and top predicted canonical pathways affected by the altered expression of genes in response to the treatment of the leaf extract in HepG2 cells. 
1 Table 2: A summary of Ingenuity Pathway Analysis (IPA) showed the top networks and top 2 predicted canonical pathways affected by the altered expression of genes in response to the 3 treatment of the leaf extract in HepG2 cells.

\section{ID}

1

2

3

3

4

5

Hereditary Disorder, Neurological Disease, Organismal Injury and

\section{Top Networks}

Lipid Metabolism, Small Molecule Biochemistry, Hematological Disease

Ophthalmic Disease, Connective Tissue Disorders, Inflammatory Disease

Digestive System Development and Function, Organ Morphology, Developmental Disorder

4 Carbohydrate Metabolism, Small Molecule Biochemistry, Free Radical Scavenging Abnormalities

\section{Score}

36

24

\section{Top canonical pathway}

$P$-value

Ratio

List of gene

Coagulation system

$$
2.80 \times 10^{-6}
$$

KNG1, SERPINC1, SERPIND1, SERPINE1, FGG, FGA

Superpathway of

$$
2.17 \times 10^{-4}
$$

DHCR24, LSS, MVK, TM7SF2

Cholesterol Biosynthesis

Intrinsic Prothrombin

$2.92 \times 10^{-4}$

4/37 (0.108)

KNG1, SERPINC1, FGA, FGG

Activation Pathway

Immune protection /

$2.28 \times 10^{-3}$

4/109 (0.037)

LEAP2, IFNGR1, ANXA3, MX1

antimicrobial response

Xenobiotic Metabolism

Signaling

$$
2.41 \times 10^{-3} \quad 6 / 304(0.020)
$$

ALDH6A1, ALDH9A1, EPHX1, CYP24A1, ADH6, GSTM4

\footnotetext{
${ }^{+}$A score of 2 or higher indicates at least $99 \%$ confidence of not being generated by random

5 chance and higher scores indicate a greater confidence.
} 


\section{1}

Analyses of lipid peroxidation, antioxidant enzymes and ROS

Figure 1(A-F): Analyses of lipid peroxidation, antioxidant enzymes and reactive oxygen species (ROS) in untreated, untreated $+\mathrm{H}_{2} \mathrm{O}_{2}$-induced and leaf-pre-treated $+\mathrm{H}_{2} \mathrm{O}_{2}$-induced HepG2 cells. Figure 1(A-B): The effects of the leaf extract on lipid peroxidation, measured as MDA levels (Figure 1A) and 4-HNE protein adduct level (Figure 1B) in HepG2 cells. Results for MDA levels were expressed as nmol MDA equivalents/mg of protein while 4-HNE levels were expressed as nmol 4-HNE adduct/mg of protein. MDA- malondialdehyde; 4-HNE - 4hydroxynonenal Figure 1(C-E): Superoxide dismutase (Figure 1C), catalase (Figure 1D) and glutathione peroxidase (Figure 1E) activities were determined using commercial assay kits (Cayman Chemicals). Figure 1F: ROS production in HepG2 cells was measured using fluorescence multi-detection microplate reader and the results were expressed as Relative Fluorescence Unit (RFU). Values with different lower case letters are significantly different ( $p$ $<0.05)$.
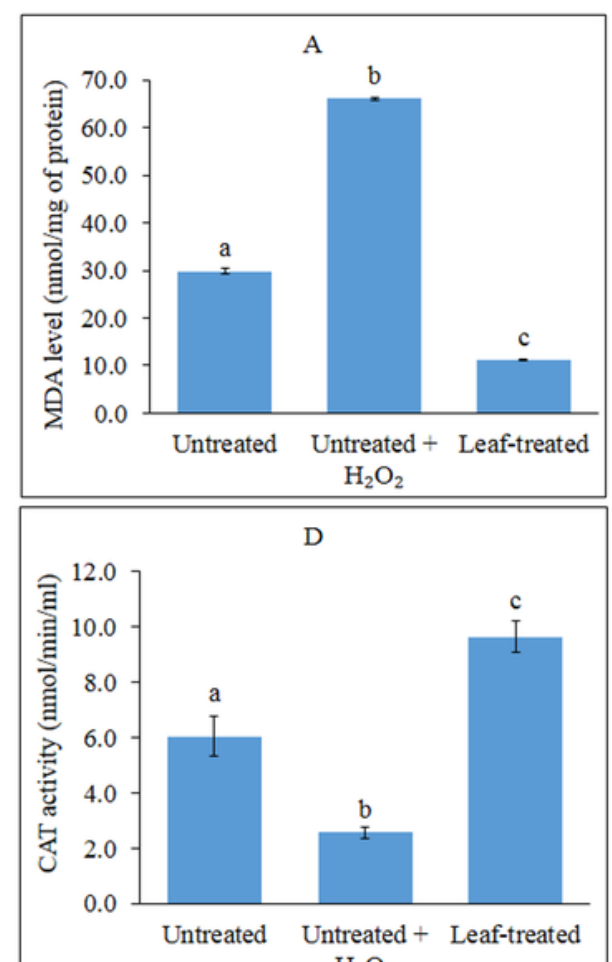
Peerf reviewing $\left.\mathrm{PDF}^{2}\right|^{2}(2015: 07: 5692: 1$
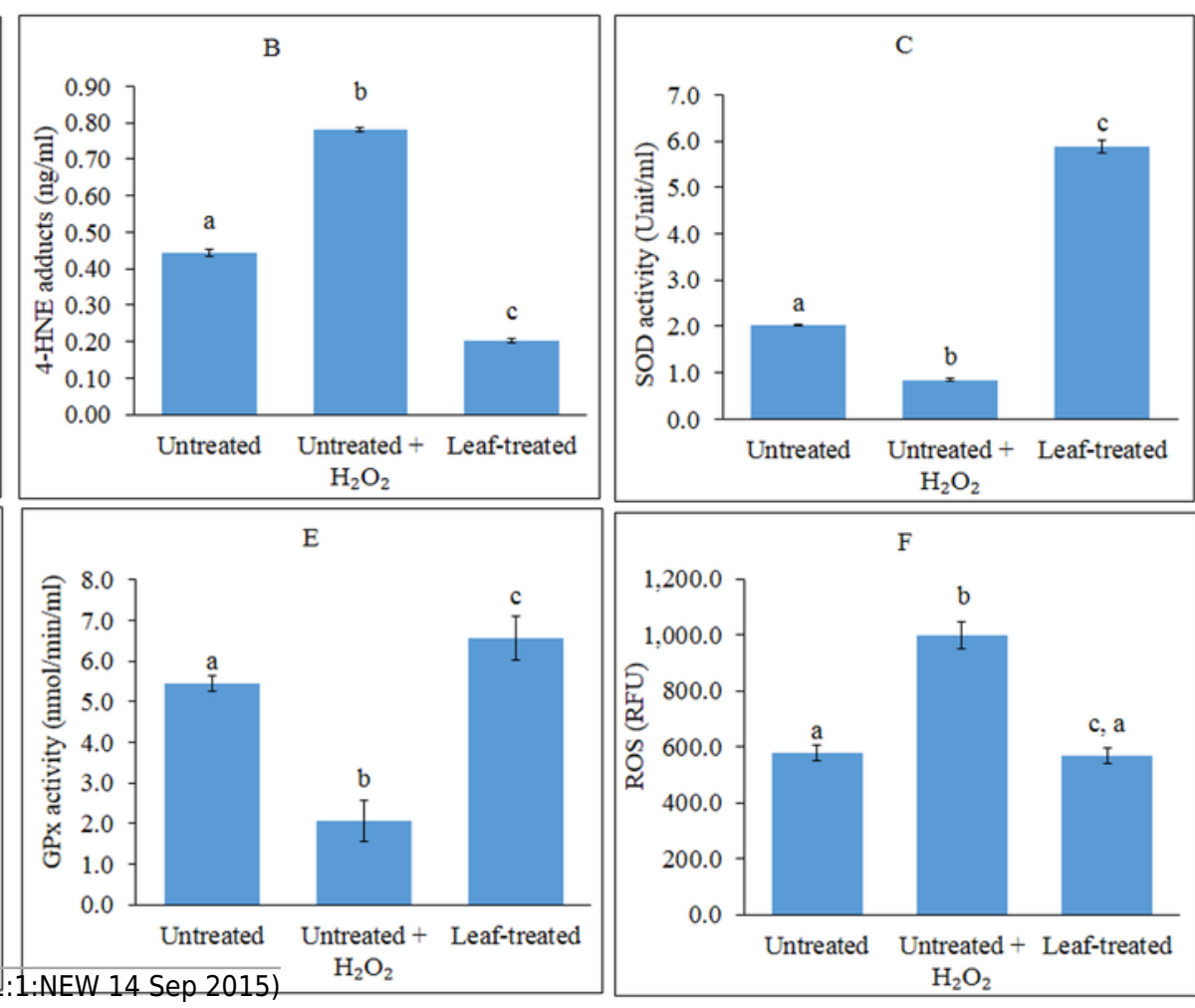

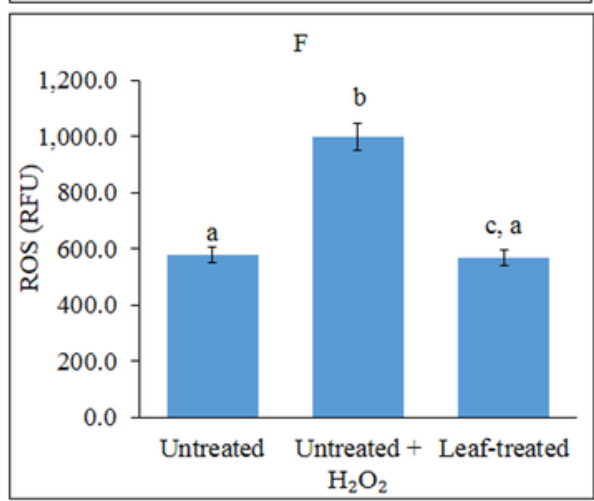




\section{2}

Image-based ROS measurement captured by fluorescence microscopy

Figure 2 (A-C): Image-based ROS measurement captured by fluorescence microscopy in HepG2 cells; (A): Untreated and unchallenged HepG2, (B): Untreated and $\mathrm{H}_{2} \mathrm{O}_{2}$-challenged HepG2 and (C): Leaf-pre-treated and $\mathrm{H}_{2} \mathrm{O}_{2}$-challenged $\mathrm{HepG} 2$.
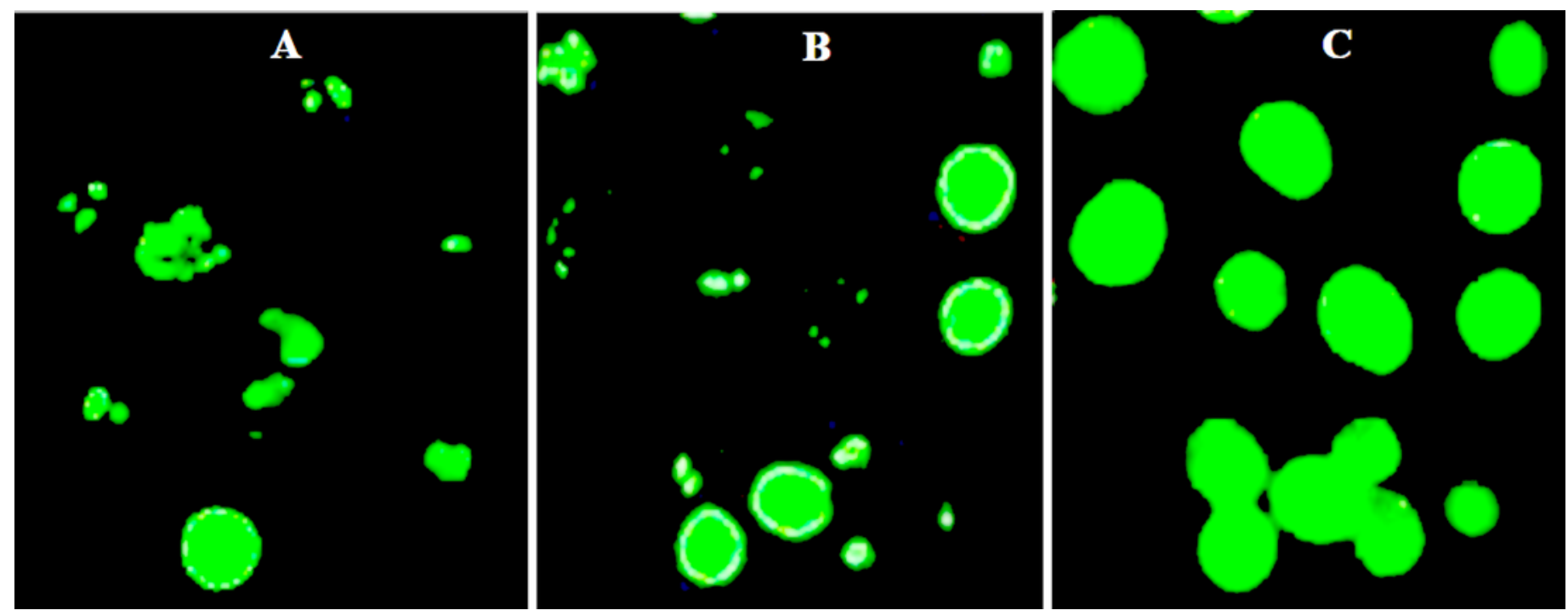


\section{3}

PCA plot

Figure 3A: A Principal Component Analysis (PCA) plot generated using Partek software of HepG2 cells grown in presence or absence of the methanol leaf extract of $T$. indica. (Data are clustered based on three biological replicates $(n=3)$ of control and treated samples. Arrays for the untreated group are in blue and those for the treated group are in green. Each ball represents a sample. Figure 3B: Hierarchical clustering of highly significant genes that are associated to different pathways generated by Genesis software. The gene expression was regulated in response to the treatment with leaf extract on HepG2 cells. The regulation pattern was differentiated with 2 colours; green for down regulation and red for up regulation. The clustering was generated using Genesis software.
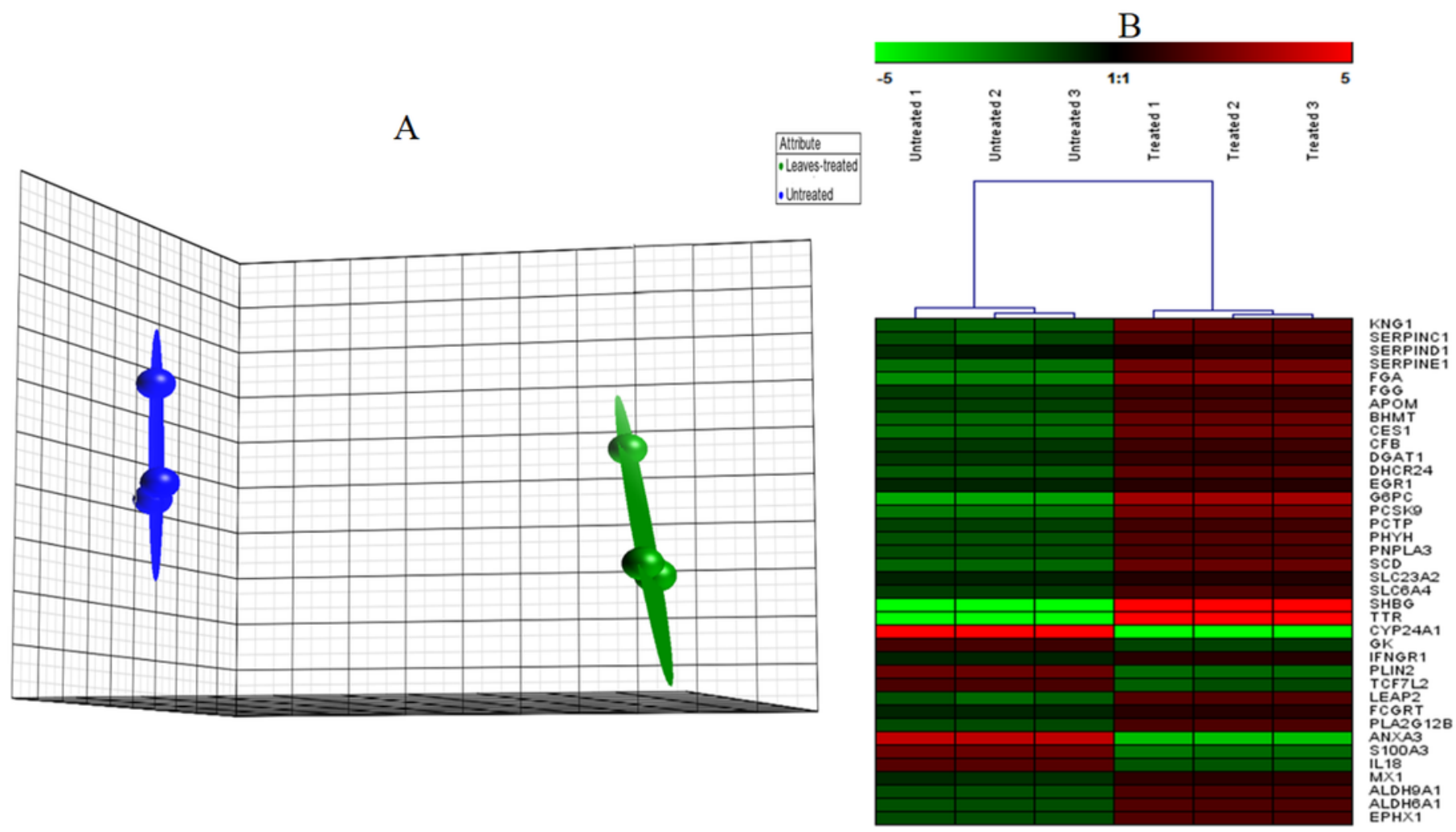


\section{4}

Validation of microarray data using qRT-PCR

Figure 4: Validation of the microarray data using qRT-PCR. The bar chart shows the gene expression patterns (presented as fold change) of selected significantly regulated genes calculated using qRT-PCR and microarray analysis. The down-regulated genes selected were CYP24A1, ANXA3 and AREG, while the up-regulated genes were LEAP2, FGA, FGG, SERPINE1, IFNGR1, MVK, DHCR24, ALDH6A1 and ADH6. All qRT-PCR data were normalized to that of $G A P D H$, a housekeeping gene.

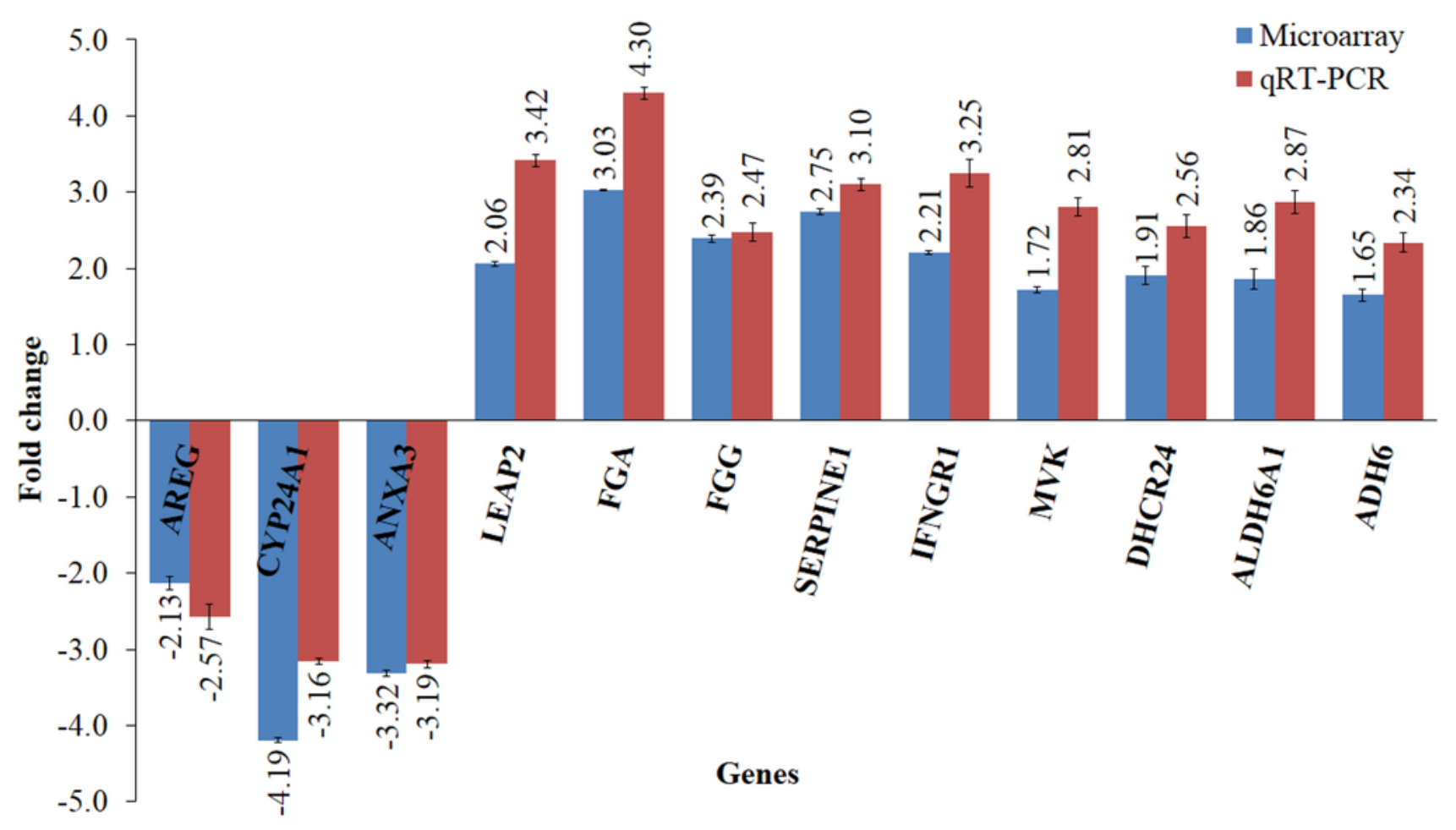




\section{5}

IPA graphical representation

Figure 5A: IPA graphical representation of the molecular relationships between the significantly regulated genes to the predicted canonical pathways in response to the leaf treatment in HepG2 cells. The network is displayed graphically as nodes (genes) and edges (the biological relationships between the nodes). Nodes in red indicate up-regulated genes while those in green represent down-regulated genes. Various shapes of the nodes represent functional class of the proteins. Edges are displayed with various labels that describe the nature of the relationship between the nodes. Name of genes with their corresponding abbreviations are as follows: ADH6, Alcohol dehydrogenase 6; ALDH6A1, Aldehyde dehydrogenase 6 family, member A1; ALDH9A1, Aldehyde dehydrogenase 9 family, member A1; ANXA3, Annexin A3; CYP24A1, Cytochrome P450, family 24, subfamily A, polypeptide 1; $D H C R 24$, 24-dehydrocholesterol reductase; EPHX1, Epoxide hydrolase 1; FGA, Fibrinogen alpha chain; FGG, Fibrinogen gamma chain; GSTM4, Glutathione S-transferase mu 4; IFNGRI, Interferon gamma receptor 1; KNG1, Kininogen 1; LEAP2, Liver-expressed antimicrobial peptide; LSS, Lanosterol synthase; MVK, Mevalonate kinase; MX1, Myxovirus resistance 1; SERPINC1, Serpin peptidase inhibitor, clade C (antithrombin), member 1; SERPIND1, Serpin peptidase inhibitor, clade D (heparin cofactor), member 1, SERPINE1, Serpin peptidase inhibitor, clade E (Nexin, Plasminogen activator inhibitor, type 1), member 1; TM7SF2, Transmembrane 7 superfamily member 2. Figure 5B: IPA graphical representation showing the effect of significantly regulated genes, ALDH6A1, ALDH6 and GSTM4 in the detoxification process of 4-HNE and MDA. This figure demonstrates that the three genes are involved in the xenobiotic metabolism signaling pathway as on one of the top canonical pathway generated by IPA. The process is displayed graphically as nodes (genes) and edges (the biological relationships between the nodes). Nodes in red indicate up-regulated genes. Various shapes of the nodes represent functional class of the proteins. Edges are displayed with various 
labels that describe the nature of the relationship between the nodes. Figure 5C: IPA graphical representation of the molecular relationships between KNG1, SERPINE1, SERPINC1, SERPIND1 and Fibrinogen that are involved in "Coagulation System", the top predicted canonical pathway in HepG2 cells affected by the methanol leaf extract of $T$. indica. The network is displayed graphically as nodes (genes) and edges (the biological relationships between the nodes). Nodes in red indicate up-regulated genes. Various shapes of the nodes represent functional class of the proteins. Edges are displayed with various labels that describe the nature of the relationship between the nodes. Name of genes/proteins with their corresponding abbreviations are as follows: $A 2 M$, Alpha-2-macroglobulin; BDK, Bradykinin; $B D K R$, Bradykinin receptor; F2, Coagulation factor II (thrombin); F2a, Coagulation factor Ila (thrombin); F2R, Coagulation factor II receptor; F3, Coagulation factor III (thromboplastin, tissue factor); F5a, Coagulation factor V (proaccelerin, labile factor); F7, Coagulation factor VII (serum prothrombin conversion accelerator); F7a, Coagulation factor VIla (serum prothrombin conversion accelerator); F8, Coagulation factor VIII (procoagulant component); F8a, Coagulation factor VIIIa (procoagulant component); F9, Coagulation factor IX; F9a, Coagulation factor IXa; F10, Coagulation factor X; F10a, Coagulation factor Xa; F11, Coagulation factor XI; F11a, Coagulation factor Xla; F12, Coagulation factor XII (Hageman factor); F12a, Coagulation factor XIla (Hageman factor); F13- Coagulation factor XIII; F13a, Coagulation factor XIIla; KLKB1a, Kallikrein B plasma 1a; PLG, Plasminogen; SERPINA1, Serpin peptidase inhibitor, clade A, member 1; SERPINA5, Serpin peptidase inhibitor, clade A, member 5; SERPINF2, Serpin peptidase inhibitor, clade F, member 2; TFPI , Tissue factor pathway inhibitor; THBD, Thrombomodulin; TPA, Tissue plasminogen activator; UPA, Urokinase plasminogen activator; UPAR, Urokinase plasminogen activator receptor; vWF, von Willebrand factor. 

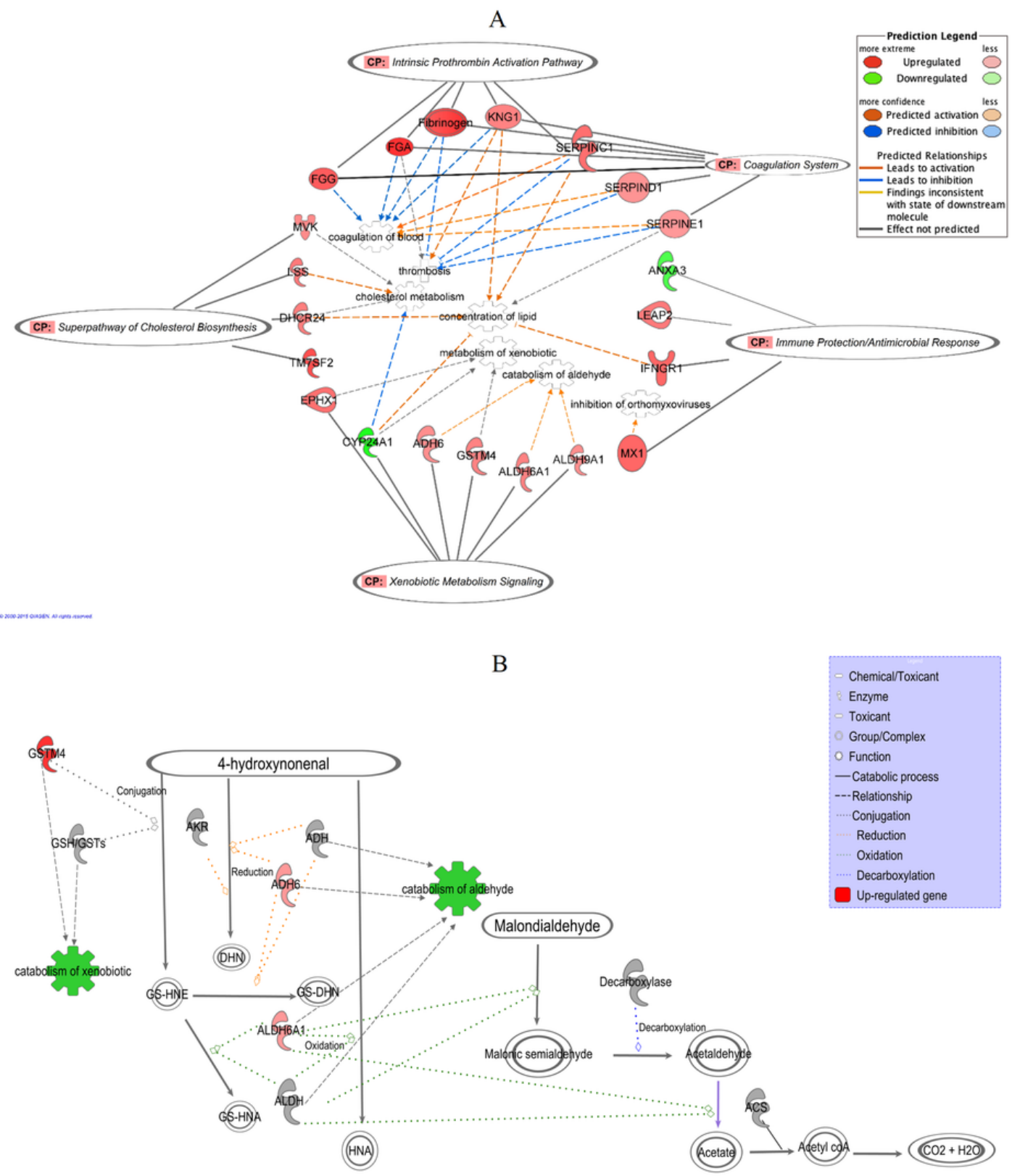

C
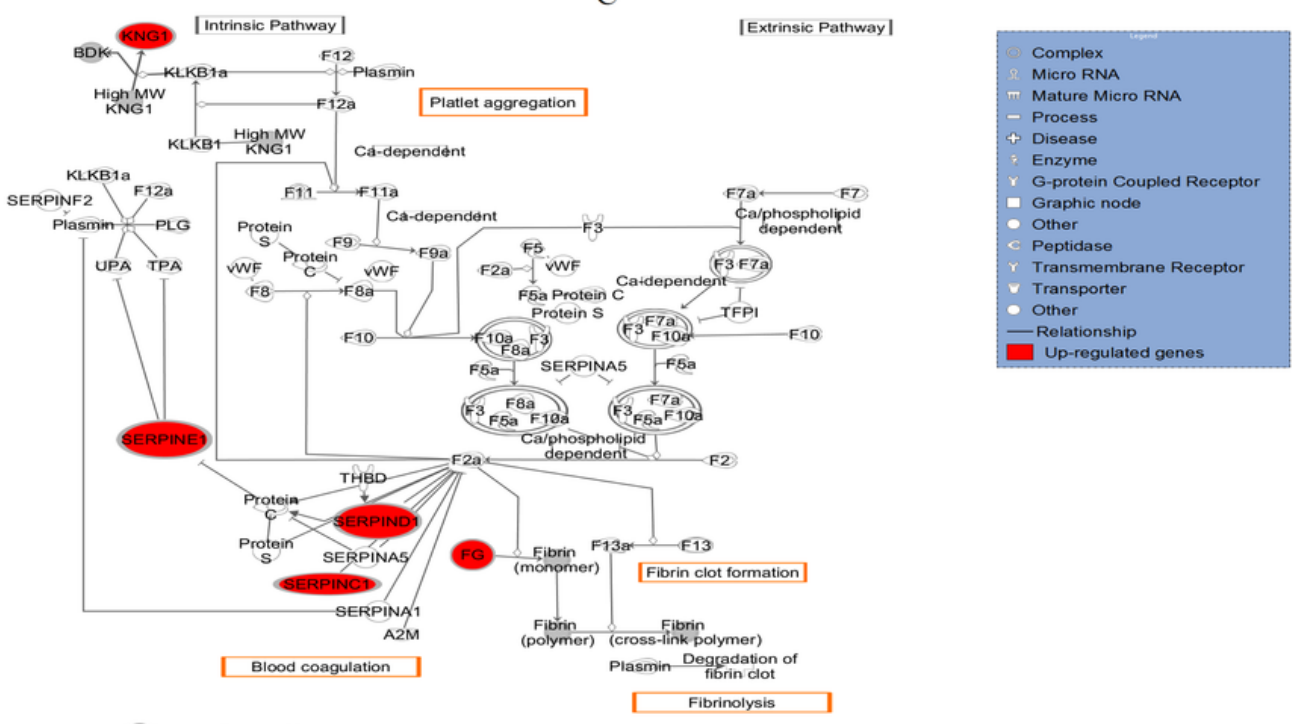

BDK UPA F2A 
6

ELISA analyses of selected proteins

Figure 6A: Enzyme-Linked Immunosorbent Assay (ELISA) analyses of the human IFNGR1, LEAP2, SERPINE1, ANXA3, KNG1, MX1, FGG, MVK, ALDH6A1 and ADH6 antibodies level in the untreated and leaf-treated HepG2 cells. ELISA analyses were done according to manufacturer's protocols (Cloud-clone, Texas, US and Cusabio Biotech, Wuhan, China). Bars not sharing the same superscript letter indicate significant difference at $p<0.05$ Figure $6 \mathrm{~B}$ : Up regulation of IFNGRI (a) and SERPINEI (b) after treatment with $\mathrm{IC}_{20}$ concentration of the leaf extract for 24 hours. Protein levels were measured with specific antibodies by western blot analysis; $\beta$-actin was the loading control. Untreated cells were used as control. The experiments were repeated in triplicates and the representative blot was shown. Bars not sharing the same superscript letter indicate significant difference at $p<0.05$ 


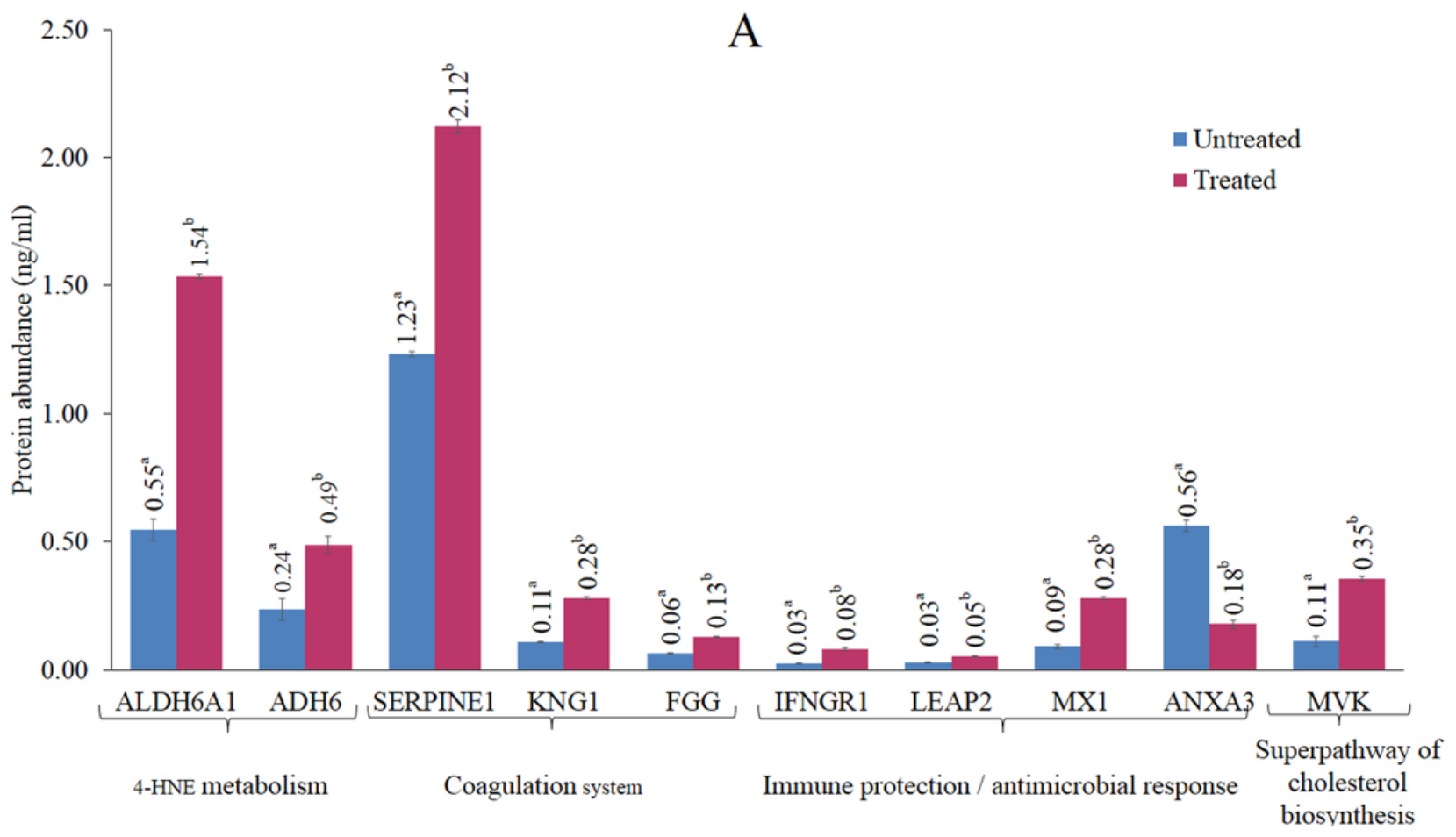

B
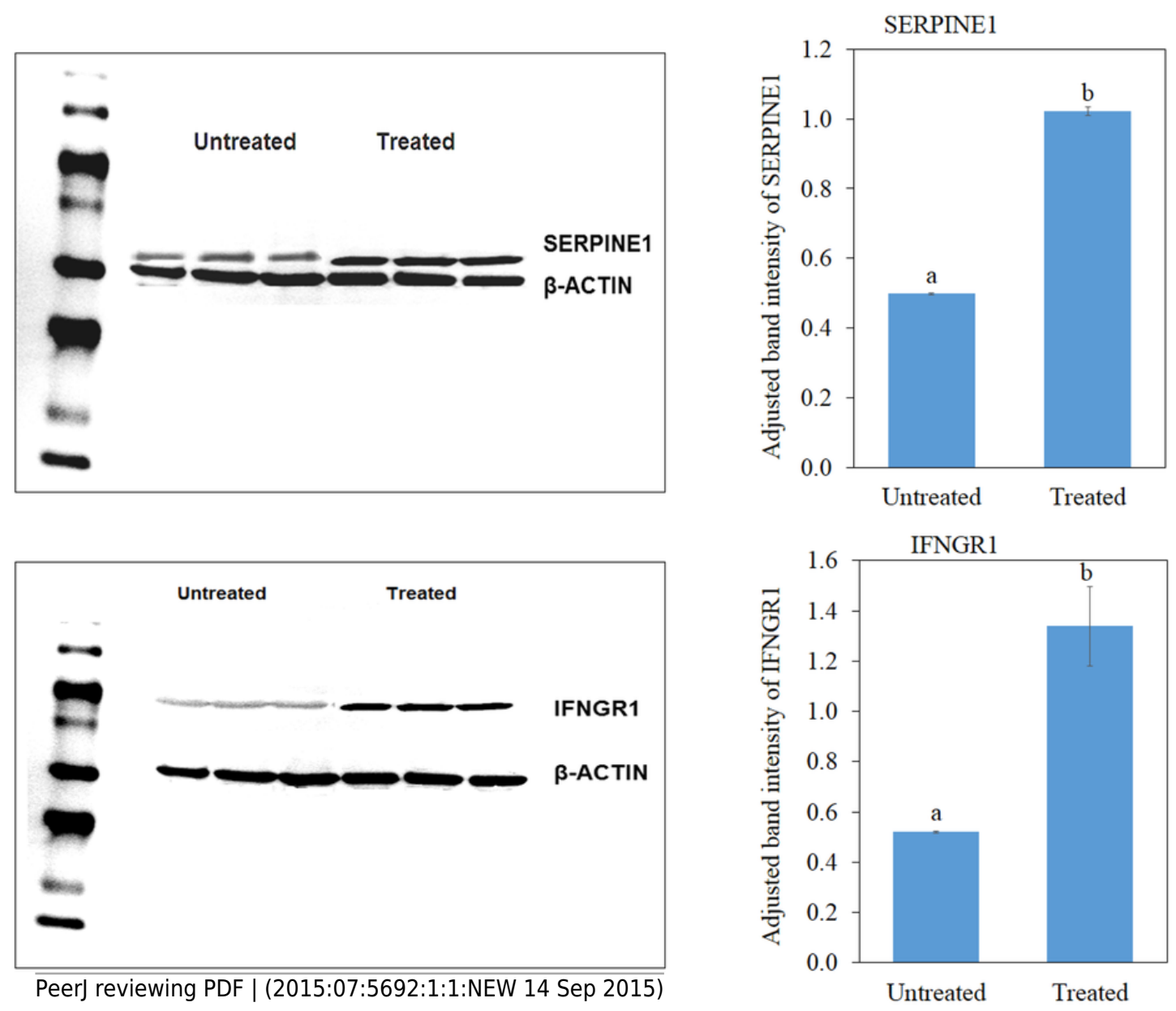